\title{
Summary for the Next Generation Nuclear Plant Project In Review
}

September 2010

The INL is a

U.S. Department of Energy National Laboratory

operated by

Battelle Energy Alliance

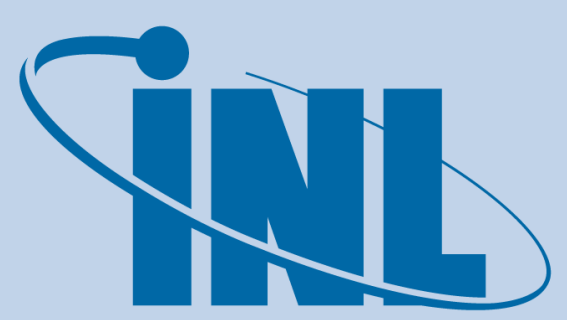

Idaho National Laboratory

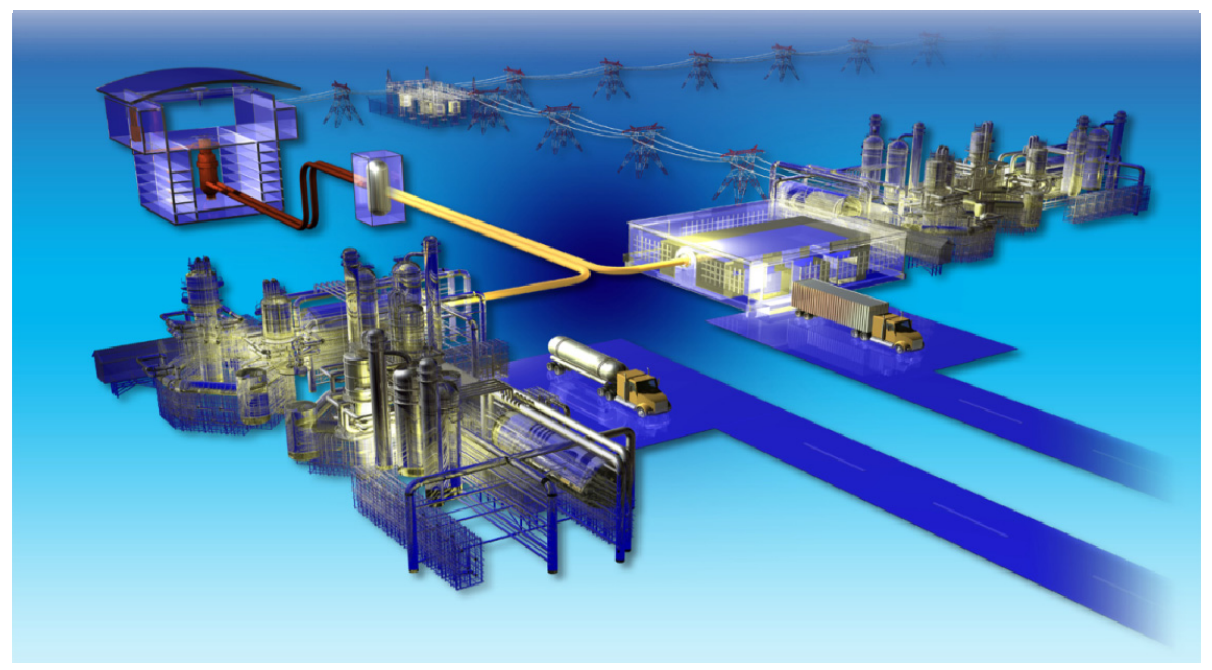




\section{DISCLAIMER}

This information was prepared as an account of work sponsored by an agency of the U.S. Government. Neither the U.S. Government nor any agency thereof, nor any of their employees, makes any warranty, expressed or implied, or assumes any legal liability or responsibility for the accuracy, completeness, or usefulness, of any information, apparatus, product, or process disclosed, or represents that its use would not infringe privately owned rights. References herein to any specific commercial product, process, or service by trade name, trade mark, manufacturer, or otherwise, does not necessarily constitute or imply its endorsement, recommendation, or favoring by the U.S. Government or any agency thereof. The views and opinions of authors expressed herein do not necessarily state or reflect those of the U.S. Government or any agency thereof. 


\title{
Summary for the Next Generation Nuclear Plant Project in Review
}

September 2010

\author{
Idaho National Laboratory \\ Next Generation Nuclear Plant Project \\ Idaho Falls, Idaho 83415
}

Prepared for the

U.S. Department of Energy

Office of Nuclear Energy

Under DOE Idaho Operations Office

Contract DE-AC07-05ID14517 

Next Generation Nuclear Plant Project

Summary for the Next Generation Nuclear Plant Project in Review

INL/EXT-10-19142

Revision 1

September 2010

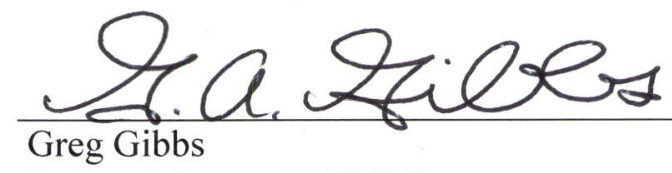

Project Director, NGNP Program

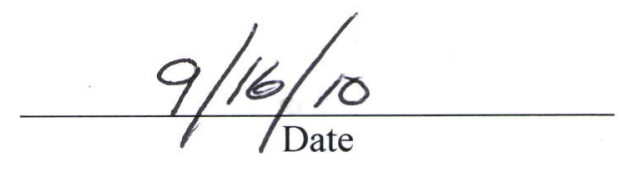



Note: The tab Attachments to

this paper may be updated as

new information within

calendar year 2010 becomes

available.

\section{EXECUTIVE SUMMARY}

This report summarizes the major progress that the Next Generation Nuclear Plant (NGNP) Project has made toward developing and commercializing the high temperature gas reactor (HTGR) technology. Significant research and development (R\&D) progress has been made in addressing key technical issues for qualification of the HTGR fuel and graphite, codification of high temperature materials, and verification and validation of design codes. Design has progressed through the pre-conceptual stage for several concepts proposed by three design teams. This design work has provided a foundation for the ongoing R\&D activities, assessment of technical risks and development of plans for management of these technical risks. Work is also progressing in heat transfer/transport design and testing and development of the high temperature steam electrolysis hydrogen production process. A viable licensing strategy has been formulated in coordination with the Nuclear Regulatory Commission (NRC) and the Department of Energy (DOE). White papers covering key licensing issues have been and will continue to be submitted and necessary discussions of these key issues have begun with the NRC. Development of a public-private partnership between the DOE and industry is needed to complete the NGNP Project objectives as established in the 2005 Energy Policy Act (EPAct).

The NGNP Project has evaluated the technical and economic viability of the HTGR design as a non$\mathrm{CO}_{2}$ emitting source of energy for a wide range of industrial processes. Review of this work in discussions with potential end users has identified significant interest, and preliminary assessments have identified a large and viable potential market for the technology. These interactions and assessments of potential markets and preliminary economics provide a foundation for making decisions on technical requirements for the HTGR module designs as the NGNP Project moves forward.

In several of the tasks reported herein, engineering judgment has been applied in assessing the market potential of the HTGR technology and its potential role in supporting government policies (e.g., reducing emissions and improving energy security). These judgments are necessary to assess the market potential and perform preliminary economic analyses of specific applications. Clearly, the actual market potential and policy benefits will be dependent on the specific government policies and the economic conditions that shape the business case for specific applications. These assessments will be updated as the policies evolve and the business environment changes.

Irrespective of the projected number of HTGR reactor modules and plants that are estimated based on the above, a major constraint to the build out of HTGRs or any major energy technology is the ability of the industrial infrastructure to respond to and support that build out - both people and industrial capability and capacity. An assessment of the current industrial infrastructure and what may be required is currently in process and will be reported as an update.

The overall functional and performance requirements derived from these studies provide the basis for detailed design specifications to be developed by the nuclear systems suppliers in cooperation with the future HTGR plant owners. In contrast to using light water reactors (LWRs) for electric power generation, 
it is anticipated that as the high temperature process heat and related markets mature and the actual owners step forward to invest, a spectrum of designs will emerge that best fit each market. A primary objective of the NGNP Project is to envelop the most important of these functional and performance requirements in its supporting development work, and in selecting a representative first-of-a-kind application that provides a demonstration useable to the broadest possible future market.

Although important engineering work has been completed by the NGNP Project, the development of the first-of-a-kind HTGR design has not progressed beyond the preconceptual stage. Limited progress in design and engineering is the result of suspension of design activities while DOE confirmed industry interest including the cost-share model to execute the NGNP Project. An interim step was taken by DOE in the early part of calendar 2010 to place a cooperative agreement with the General Atomics team derived from the Financial Offer of Assistance (FOA) issued in September 2009 to perform conceptuallevel design work for the NGNP Project based on the prismatic block reactor concept. This work is scheduled to complete toward the end of calendar year 2010. DOE was not able to come to a similar agreement with a reactor supplier for conceptual-level design of a plant based on the pebble bed reactor concept. This results in a delay in developing the pebble bed based plant design. There are compelling reasons for the NGNP Project to continue to develop both designs. Even though the South African government has suspended financial support of Pebble Bed Modular Reactor (PBMR (Pty) Ltd., prior development work and the pebble bed technology can be made available to other major reactor suppliers through licensing agreements; such discussions are underway.

The discussions of the NGNP Project and the HTGR suppliers with potential owner/operators and end users of the HTGR design find that all interested parties conclude that both the prismatic and pebble bed reactor concepts should be carried forward in the NGNP Project. This provides a choice and competition in application of the technology. The NGNP Project has assessed whether there are technical bases for selection of one concept over the other and concluded that there is not now nor is it likely such bases will evolve. In fact, the assessment concludes that carrying both designs forward reduces NGNP Project risks by providing alternatives if significant problems are encountered with either of the concepts in the design and licensing processes. This assessment also concluded that such a selection is appropriately the purview of the eventual owner of the plant.

Advancement of the designs for both the pebble bed and prismatic reactor based plants sufficient to identify and complete the design of safety related structures, systems, and components and those important to safety is needed to support development of the Combined License Application(s) (COLA) for the first-of-a-kind plant(s). To meet the schedule provisions of the EPAct (initial operation of the plant in 2021); this work needs to be completed in the 2013 time frame for submittal of the COLA(s) in 2014.

The private sector, represented by the NGNP Industry Alliance Limited ${ }^{\mathrm{a}}$, has proposed a NGNP Project Implementation Strategy that promotes development of a public-private partnership and proposes processes to ensure that both the government and the private sector perspectives are included in making major decisions on the paths forward for the NGNP Project. This strategy includes carrying two plant designs (pebble bed-based and prismatic block-based reactor designs) to the point where a decision is to be made on building one or both plants. This strategy is different from the current DOE strategy, which expects to make a decision on the design to carry forward in the NGNP Project based on a competitive "down-select" in FY2011. The NGNP Industry Alliance and DOE should reconcile their recommended strategies and take the steps necessary for near term formation of the public-private partnership to provide

a The NGNP Industry Alliance Limited. is an industry consortium formed with the assistance of the Idaho National Laboratory as directed by EPAct 2005 and the Battelle Energy Alliance contract with DOE. The Alliance members include energy end-users representing the petrochemical and petroleum industries, a nuclear owner/operator, nuclear system suppliers, a nuclear fuel and equipment vendor, and an architect-engineer/constructor. 
both the government and the industry perspectives in directing and informing the future progress of the NGNP Project. The work completed to date by the NGNP Project is sufficient to inform these efforts.

A fundamental observation from extensive discussion with industry companies represented by the NGNP Industry Alliance is that the private sector will enter into substantial cost-share with government only if a public-private partnership is formed providing the framework and authorities for the government and industry to make important decisions and manage the NGNP Project. Additionally, the private sector considers it unwarranted to make an early design down-selection in FY2011 as currently planned by the DOE. The private sector considers that competitive and complementary designs through preliminary design are necessary to support completion of licensing pre-application activities and preparation of COLA(s). Presuming comparable functional and performance capabilities, the industry anticipates that design down-selection will be based primarily on regulatory infrastructure maturation for advanced reactors, the low risk potential to certify and license the design, and the economics of the planned business case, none of which can be adequately assessed until the preliminary designs are nearing completion. Further, the industry anticipates that down-selection will be made by a combination of the future owner, the license applicant and the energy end-user, i.e., those entities that will have the financial stake in constructing and operating the first reactor module. In practical fact, the industry anticipates that the decision to complete design, license and build of the first-of-a-kind reactor module will be made concurrently with the decision to build several subsequent modules since the business case for a single module is not considered viable.

Reiterating the conclusions of the 2009 Status Report, the successful deployment of NGNP will hinge on the following:

- DOE and the NGNP Industry Alliance — or other qualified partner(s) - implementing a public-private partnership

- A commitment by the Administration, Congress, and the private sector to share up-front risks

- Continuity of funding over multiple years.

By taking immediate action to achieve these ends, DOE and industry can position the United States to realize the economic, environmental, and energy security benefits of HTGR technology. 


\section{CONTENTS}

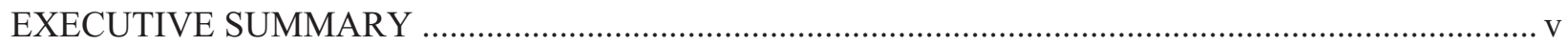

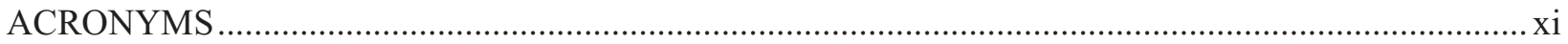

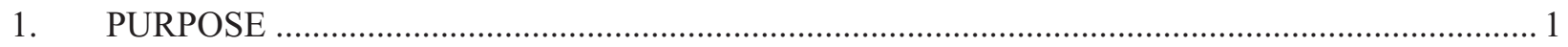

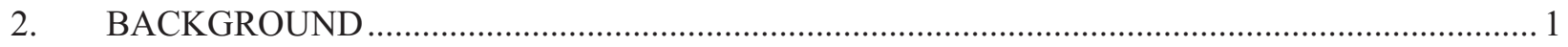

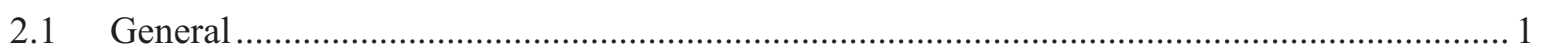

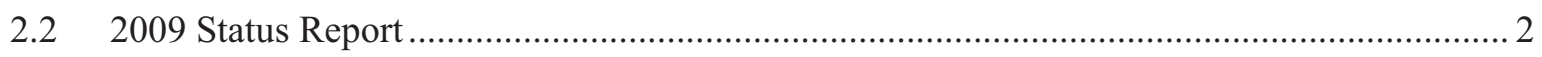

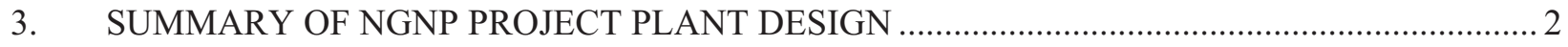

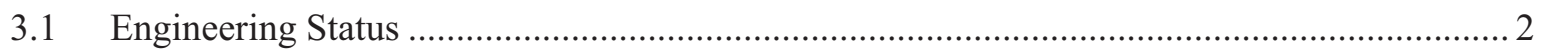

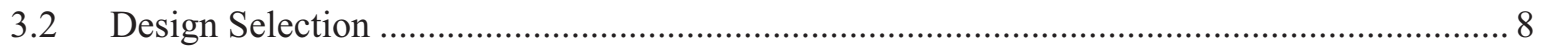

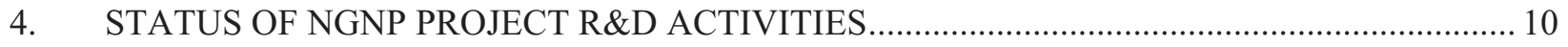

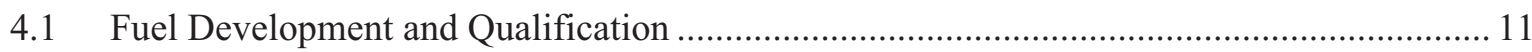

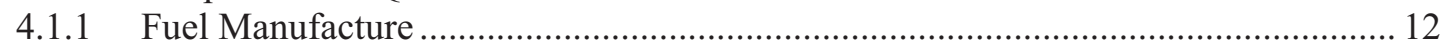

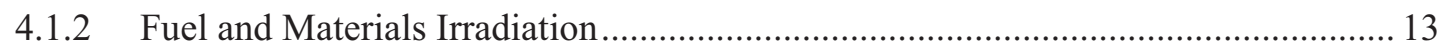

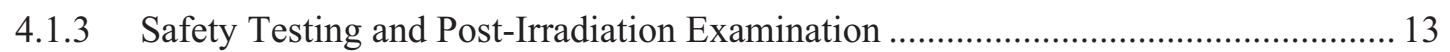

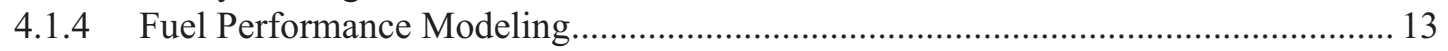

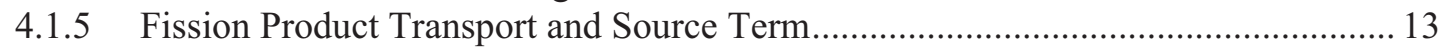

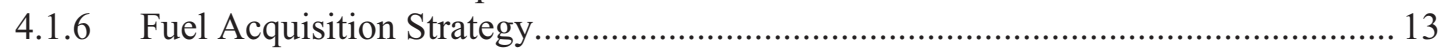

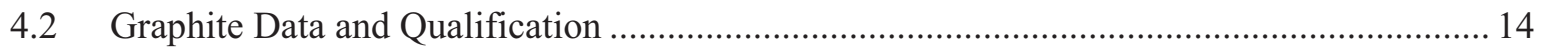

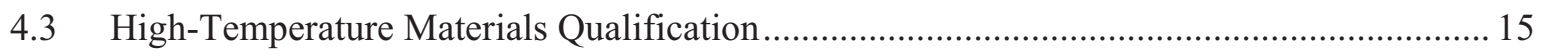

4.4 Design and Safety Methods Development and Validation ................................................ 15

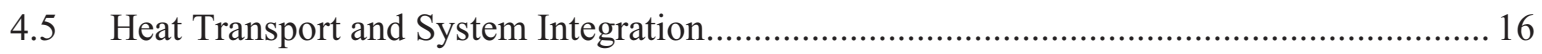

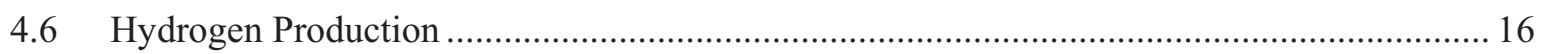

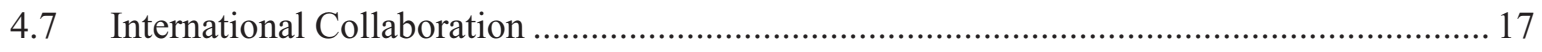

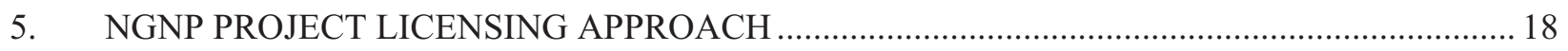

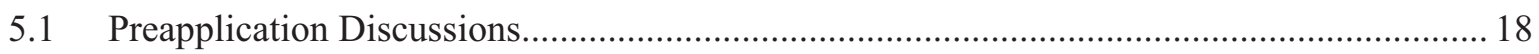

5.210 CFR 52 COLA Content Guide and Preparation........................................................ 18

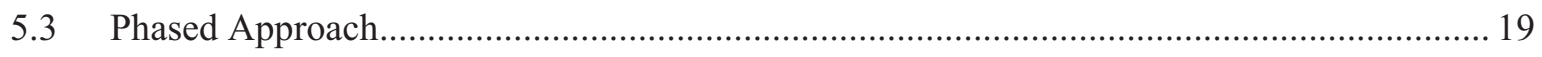

6. STATUS OF NGNP PROJECT RISK MANAGEMENT PROGRAM......................................2 21

7. THE HTGR POTENTIAL MARKET AND PRELIMINARY ECONOMICS .............................. 23

8. A TECHNOLOGY-BASED STRATEGY FOR TRANSFORMING THE U.S. ENERGY

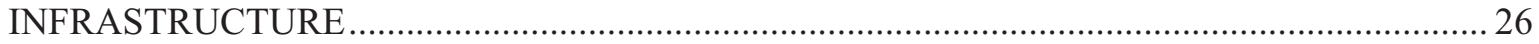

9. INFRASTRUCTURE REQUIREMENTS TO SUPPORT HTGR TECHNOLOGY DEPLOYMENT . 30

10. A COMPARISON OF THE DOE AND NGNP INDUSTRY ALLIANCE PROJECT IMPLEMENTATION STRATEGIES 


\section{FIGURES}

Figure 1. WEC/PBMR team pebble bed reactor FY 2007 NGNP preconceptual design

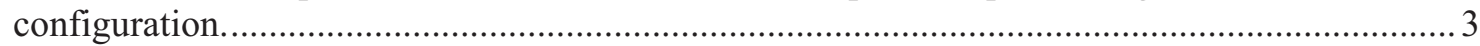

Figure 2. AREVA team prismatic reactor FY 2907 NGNP preconceptual design configuration................. 4

Figure 3. GA team prismatic reactor FY 2007 NGNP pre-conceptual design configuration. ..................... 4

Figure 4. Current WEC/PBMR conceptual configuration. ....................................................................... 5

Figure 5. Current AREVA and GA conceptual summary flowsheet................................................... 5

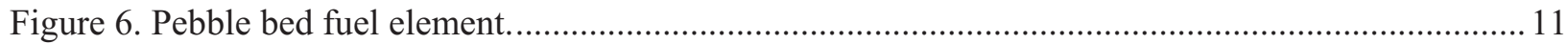

Figure 7. Prismatic reactor fuel particles, compacts and assemblies.................................................... 12

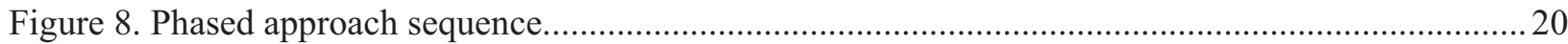

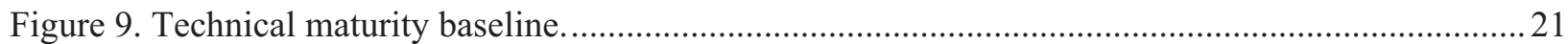

Figure 10. Price of steam generated by an HTGR and a CCGT vs. the price of natural gas and

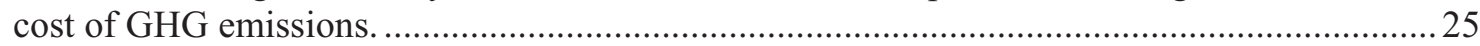

Figure 11. DOE/EIA Summary of Historical and Projected $\mathrm{CO}_{2}$ Emissions by Energy Source...............27

Figure 12. Reduction in $\mathrm{CO}_{2}$ emissions required to meet administration and congressional targets..........27

Figure 13. Results of technology based strategy application................................................................. 28 


\section{ACRONYMS}

AGR Advanced Gas Reactor

ANS American Nuclear Society

ASME American Society of Mechanical Engineers

ASTM American Society for Testing and Materials

COLA combined license application

DOE U.S. Department of Energy

EPAct Environmental Policy Act of 2005

FOA Financial Offer of Assistance

FOAK first-of-a-kind

FSAR final safety analysis report

GA General Atomics

GHG greenhouse gas

HTGR high temperature gas-cooled reactor

HTTR High Temperature Test Reactor

IHX intermediate heat exchanger

INL Idaho National Laboratory

LWR light water reactor

NGNP Next Generation Nuclear Plant

NRC Nuclear Regulatory Commission

PBMR Pebble Bed Modular Reactor

$\mathrm{R} \& \mathrm{D} \quad$ research and development

SSCs structures systems, and components

TRISO tri-isotopic

TRL Technology Readiness Level

SSC structures, systems, and components

WEC Westinghouse Electric Company 


\section{Summary for Next Generation Nuclear Plant Project in Review}

\section{PURPOSE}

The purpose of this document is to summarize the progress of the Next Generation Nuclear Plant (NGNP) Project in developing and commercializing the high temperature gas-cooled reactor design (HTGR). This progress report is comprised of this summary (Sections 2 through 10, below), which introduces the salient work and conclusions of the NGNP Project to the time of this writing as described in more detail in the tab Attachments to this Summary report covering:

- The NGNP Project 2009 Status Report (tab 2)

- Engineering Status (tab 3)

- NGNP Pre-Conceptual Design Report (tab 3a)

- Basis for NGNP Reactor Design Down-Selection (tab 3b)

- Research and Development Status (tab 4)

- Licensing Status (tab 5)

- NGNP Risk Management through Assessing Technology Readiness Status (tab 6)

- High Temperature Gas-Cooled Reactor Projected Markets and Preliminary Economics (tab 7)

- Transforming the U.S. Energy Infrastructure (tab 8)

- Infrastructure Readiness Assessment for NGNP (tab 9)

- Summary of Differences in Approach to Executing the NGNP Project. (tab 10)

\section{BACKGROUND}

\subsection{General}

The NGNP Project was initiated at Idaho National Laboratory (INL) by the DOE as part of the Generation IV Nuclear Energy Systems Technology Roadmap (Gen IV) and pursuant to the 2005 Energy Policy Act (EPAct) (Public Law 109-58). The mission of the NGNP Project is to broaden the environmental and economic benefits of nuclear energy technology to the United States and other economies by demonstrating through deployment in industrial applications its use for market sectors not served by light water reactors (LWR). Those markets typically use fossil fuels to fulfill their energy needs. Because the HTGR is helium cooled with a graphite core it can operate at reactor outlet temperatures much higher than conventional LWR technology. Accordingly, HTGRs can be used in place of fossil fuels in industrial applications and for generation of electric power, reducing or eliminating the greenhouse gas (GHG) emissions from these fuels. The use of the HTGR also provides a long term secure energy source at a stable price insulating the end user from the economic uncertainties associated with the volatility in the price and availability of fossil fuels.

In several of the tasks reported herein, engineering judgment has been applied in assessing the market potential of the HTGR technology and its potential role in supporting government policies (e.g., reducing emissions and improving energy security). These judgments are necessary to assess the market potential and perform preliminary economic analyses of specific applications. Clearly, the actual market potential 
and policy benefits will be dependent on the specific government policies and the economic conditions that shape the business case for specific applications. These assessments will be updated as the policies evolve and the business environment changes.

Irrespective of the projected number of HTGR reactor modules and plants that are estimated based on the above, a major constraint to the build out of HTGRs or any major energy technology is the ability of the industrial infrastructure to respond to and support that build out - both people and industrial capability and capacity. An assessment of the current industrial infrastructure and what may be required is currently in process and will be reported as an update.

The activities of the NGNP Project will confirm the technical and economic viability of the HTGR in meeting this mission through completion of the design development, design, licensing, construction, testing, and initial operation of the demonstration plant in an industrial application. The following sections of this report and their corresponding attachments summarize the progress of the NGNP Project in completing this effort to the date of this writing.

\subsection{Status Report}

The Attachment in tab 2 to this Summary is the NGNP 2009 Status Report. This provides a high level summary of the accomplishments of the NGNP Project through the end of fiscal year 2009. This status report provides a backdrop to the development of key aspects of the NGNP Project covered in the following sections and in the attachments.

\section{SUMMARY OF NGNP PROJECT PLANT DESIGN}

\subsection{Engineering Status}

NGNP Project Engineering contracted for preconceptual design work in FY 2007 focused on the provisions of the 2005 EPAct. The EPAct tasked the NGNP Project with demonstrating the production of hydrogen and/or electricity using an HTGR design in a plant to be sited at INL. Pursuant to this objective the NGNP Project issued a Request for Proposals for the development of preconceptual designs of HTGR plants for the production of electricity and hydrogen at INL. The NGNP Project received and evaluated several proposals. Technically acceptable proposals were received and contracts were subsequently established to complete this work in FY 2007 with three teams headed by suppliers of HTGR design. The teams included the Pebble-Bed Technology Team (principally led by Westinghouse Electric Company, LLC, (WEC) and Pebble Bed Modular Reactor Pty Ltd. (PBMR) from South Africa, AREVA NP, Inc., and General Atomics (GA). These design teams were international in nature and each consisted of multiple team members providing specific capabilities relevant to HTGR development, nuclear power applications, and hydrogen production. A total of 26 companies managed by the three teams' leaders participated in this design work.

The preconceptual design work was completed by the three design teams under the direction of NGNP Project Engineering in FY 2007. Each of the three teams and the NGNP Project prepared preconceptual design reports presenting the methods and conclusions of the work. The NGNP Project then developed a consolidated preconceptual design report, which was submitted to DOE. The preconceptual design work developed a framework in which the design and technology development of HTGR could progress and begin to develop bases for selection of the specific design and operational characteristics of the NGNP demonstration.

The scope of the pre-conceptual design work included completion of special studies to address key aspects of the NGNP (e.g., reactor type, power levels, power conversion system, and heat 
transfer/transport system designs, licensing, and end product disposition). The results of these special studies were applied to the development of a recommended design for NGNP and a commercial version of the HTGR by each contractor. These were then used to estimate costs and schedule for design, construction, licensing, startup and testing, operation, and deactivation, decontamination, and decommissioning of NGNP and an economic assessment for an Nth-of-a-kind commercial plant. A primary outcome of this work was to identify research and development (R\&D) needs, design data needs, and future studies required to support selection of key characteristics and to support the design and licensing processes for NGNP.

Figures 1 through 3 show the different design configurations proposed by the suppliers as a result of this work. The WEC/PBMR team proposed a pebble bed reactor with an annular core and a two stage compact intermediate heat exchangers (IHXs) supplying a steam generator and the hydrogen plant.

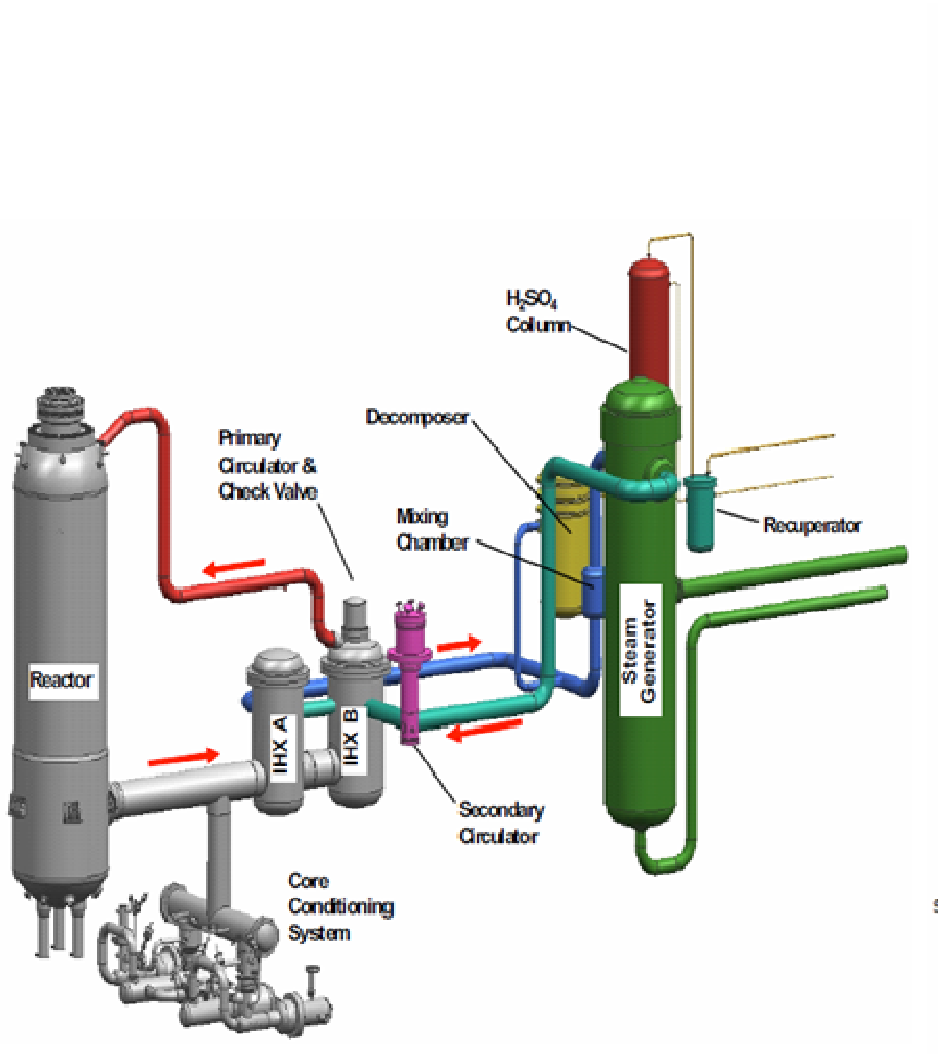

Indirect configuration producing electricity and hydrogen.

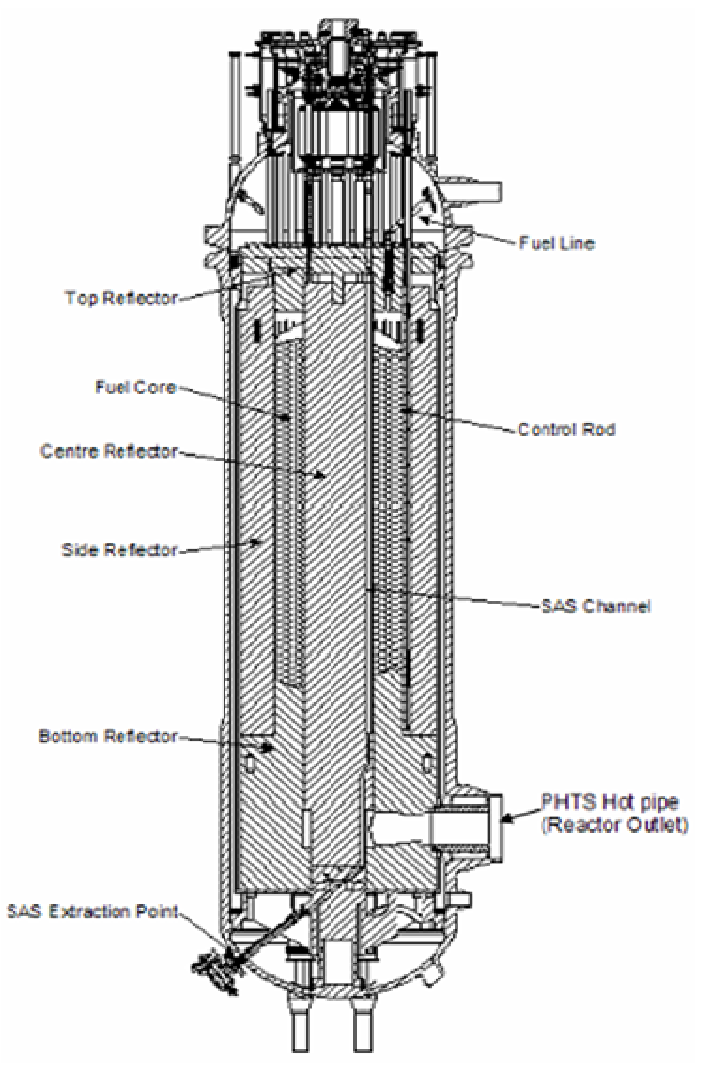

Annular Pebble Bed Reactor.

Figure 1. WEC/PBMR team pebble bed reactor FY 2007 NGNP preconceptual design configuration. 


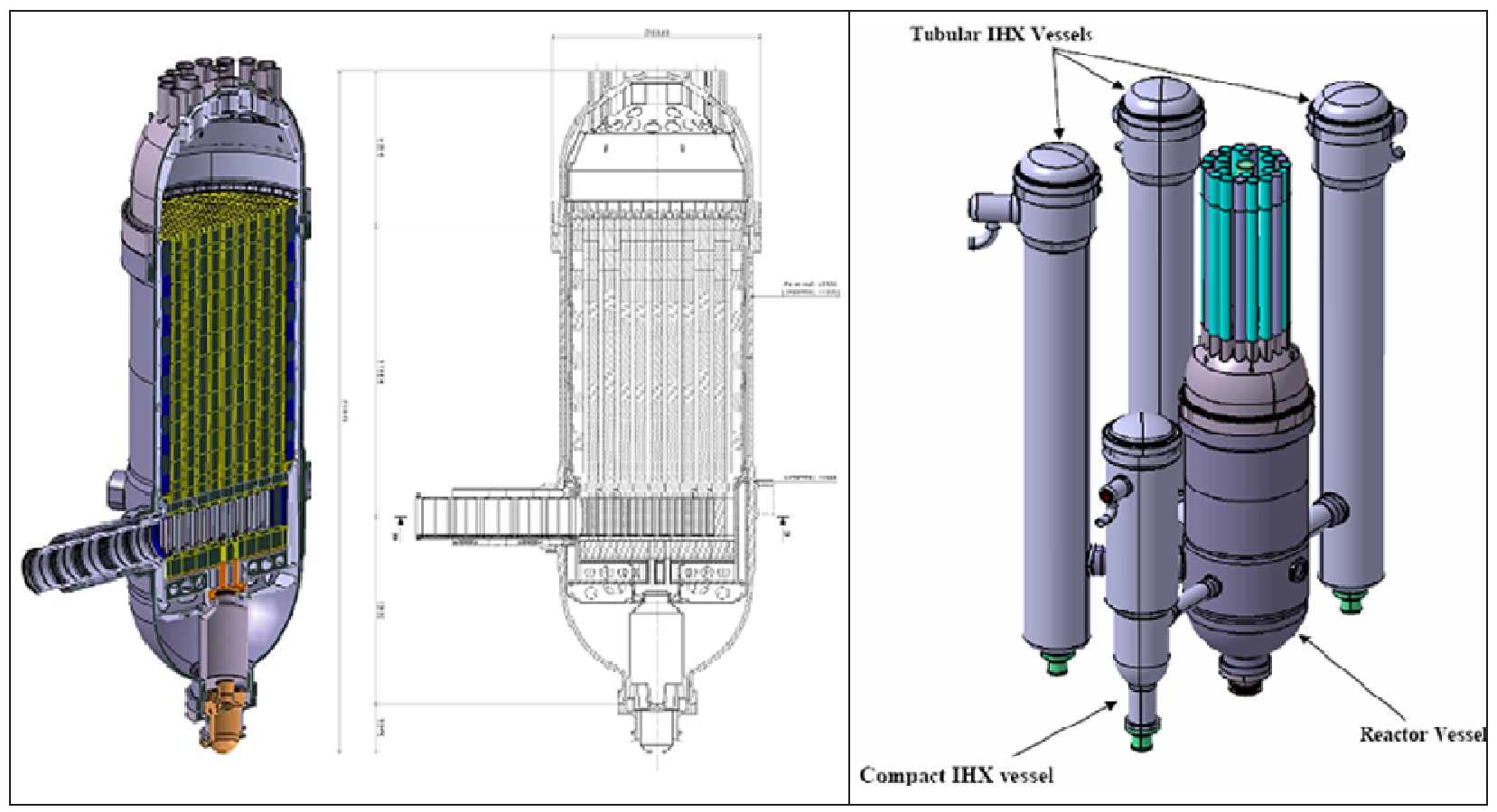

Figure 2. AREVA team prismatic reactor FY 2907 NGNP preconceptual design configuration.

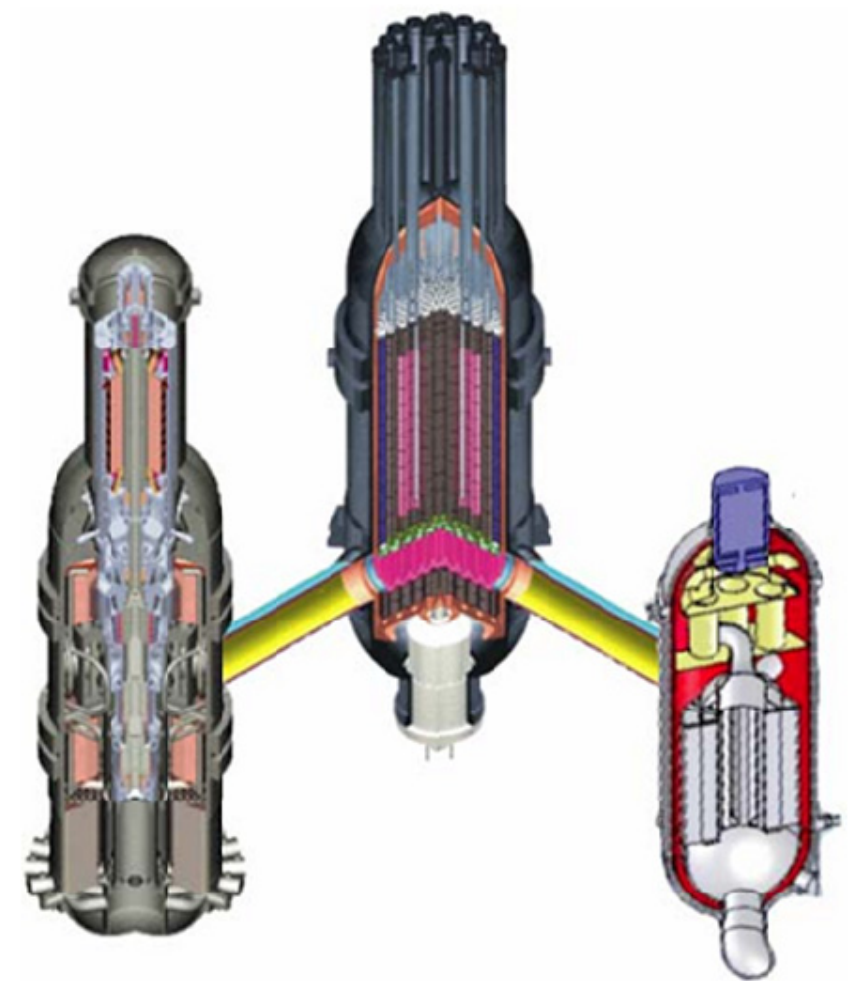

Figure 3. GA team prismatic reactor FY 2007 NGNP preconceptual design configuration. 


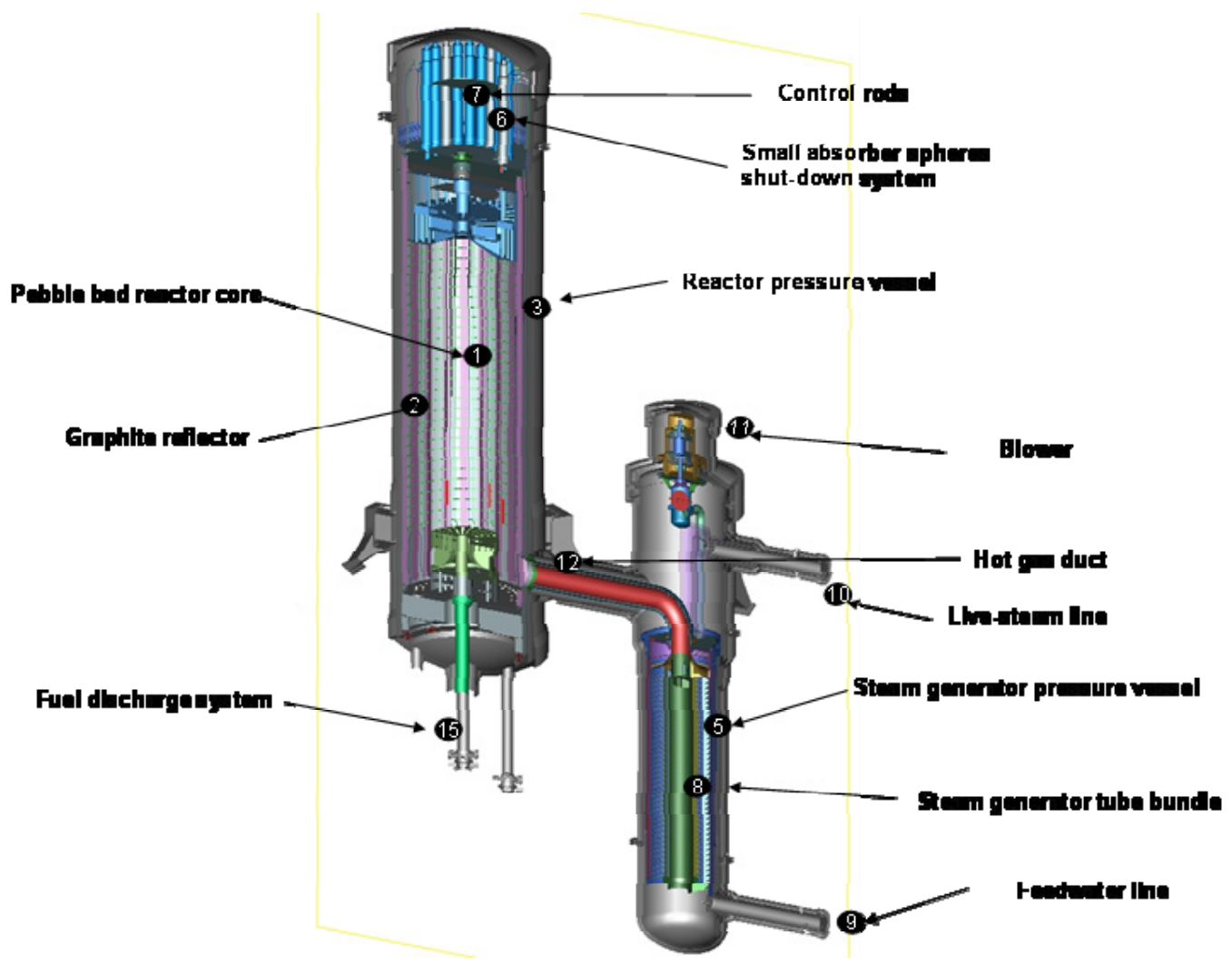

Figure 4. Current WEC/PBMR conceptual configuration.

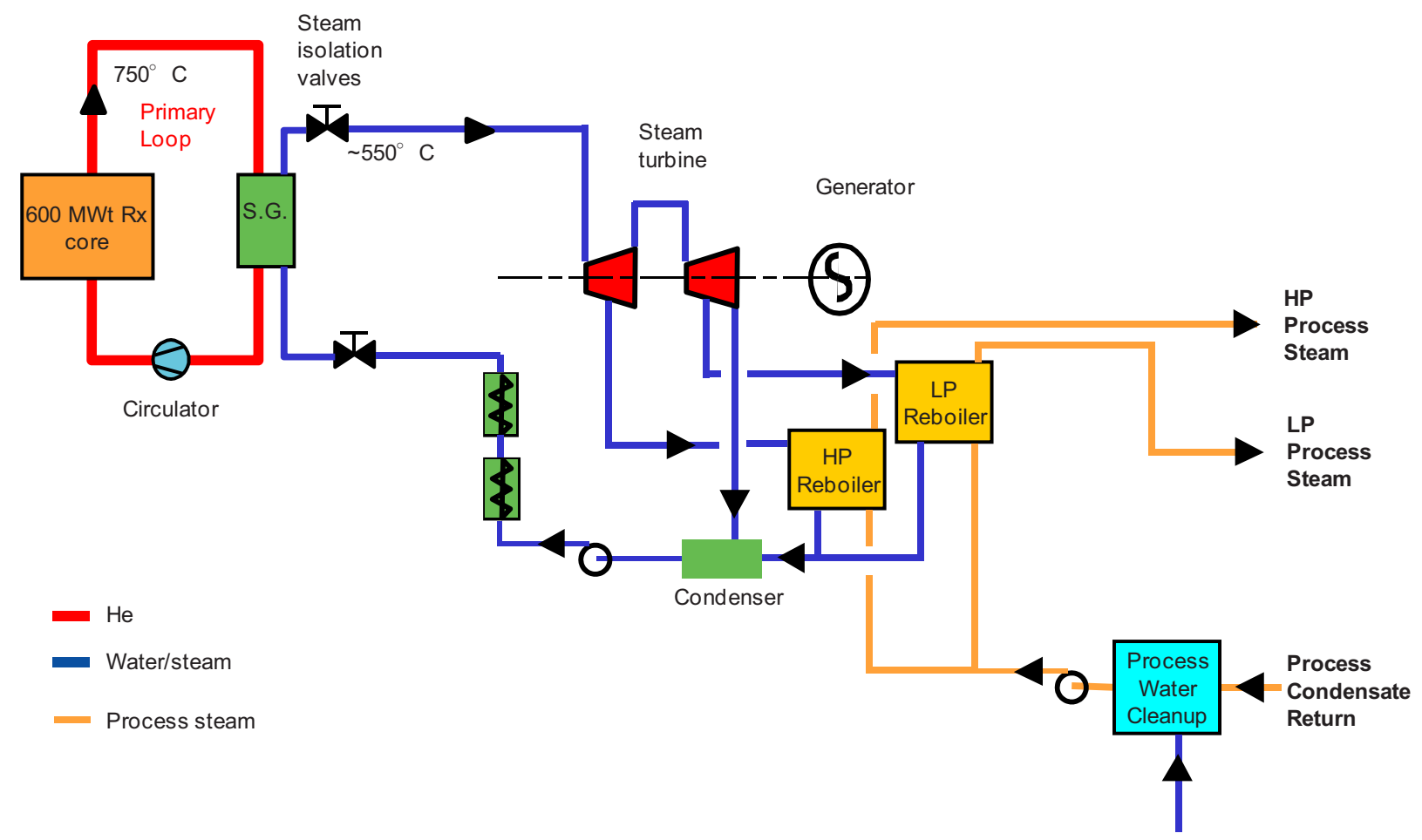

Figure 5. Current AREVA and GA conceptual summary flowsheet. 
The AREVA team proposed a prismatic block reactor supplying multiple shell and tube and compact IHXs supplying a steam generator and hydrogen plant. The GA team proposed a prismatic block reactor design with a Brayton cycle gas turbine in the primary helium loop generating electricity and a compact heat exchanger supplying the hydrogen processes. The plant ratings ranged from 500 to $565 \mathrm{MWth}$ (megawatt thermal) with reactor outlet temperatures in the 900 to $950^{\circ} \mathrm{C}$ range. All reactor designs used tri-isotopic (TRISO) fuel.

The preconceptual design work also identified the need for development of testing facilities to advance the technical readiness level of critical components and systems with important technical risk. The capability of testing large-scale components in conditions similar to that to be experienced in service is needed to support development of high-temperature gas thermal-hydraulic technologies (e.g., helium, helium-nitrogen, $\mathrm{CO}_{2}$ ) as applied in heat transport and heat transfer applications in HTGRs. Such applications include but are not limited to primary helium, secondary coolants; heat transport fluids; direct-cycle power conversion; intermediate, secondary and tertiary heat transfer; and demonstration of processes requiring high temperatures (e.g., hydrogen production). The initial need for such facilities would be to support the completion of NGNP. However, the facilities would be available for use by the full range of suppliers, end-users, government laboratories, and others in the domestic and international community supporting the development and application of HTGR design.

Subsequent to completion of the preconceptual design, evaluation of technical risks to completion of the NGNP Project in the time frame required (i.e., initial operation of the first-of-a-kind (FOAK) plant by the end of 2021), and interactions with potential end-users in the industrial sector led to revisions in the functional, operational, and siting requirements for NGNP from those applied in FY 2007. This effort was supported by a NGNP Project-initiated Senior Advisory Group made up of the HTGR suppliers and a nuclear plant owner/operator that advises the NGNP Project on the development of plant requirements and technology development strategies. The NGNP Project also interfaced with the NGNP Industry Alliance, Limited ${ }^{\mathrm{b}}$ to further define the needed characteristics of the HTGR design. The culmination of this effort concluded the following:

- The industry believes the technology provides an important energy supply option for industrial processes but to be relevant for business planning it should be available for commercial application no later than the mid-2020s.

- Multiple modules of nuclear heat supply systems will be required to satisfy the total energy needs and reliability and availability requirements of the processes

- To confirm the technical, licensing, and economic viability of the technology, the initial application of the technology should be a FOAK module with the intended purpose to become a multi-module commercial application rather than remaining solely as a demonstration plant

- Reactor outlet temperatures in the 700 to $800^{\circ} \mathrm{C}$ range would be sufficient to satisfy the initial temperature needs of industry, but pursuit of higher reactor outlet temperatures should be continued for higher temperature applications at the earliest practical time

- Steam, electricity, and hot gas are the principal forms of energy required to satisfy the first generation needs

- Along with supplying steam, electricity, and hot gas, an economic supply of hydrogen from the HTGR as the source of heat would permit the upgrade of current industrial processes to increase

b The NGNP Industry Alliance, Limited, is an industry consortium formed with the assistance of the Idaho National Laboratory as directed by EPAct 2005 and the Battelle Energy Alliance contract with DOE. The Alliance members include energy end-users representing the petrochemical and petroleum industries, a nuclear owner/operator, nuclear system suppliers, a nuclear fuel and equipment vendor, and an architect-engineer/constructor. 
efficiency and reduce GHG emissions (e.g., petrochemical processes, conversion of coal to synthetic fuels, fertilizer manufacturing).

The HTGR suppliers proposed revised designs based on these conclusions. As shown in Figures 4 and 5, the WEC/PBMR team adopted a cylindrical pebble bed core reactor design with a steam generator in the primary helium loop. This plant has a rating in the 200 to $250 \mathrm{MWth}$ range with a reactor outlet temperature of $750^{\circ} \mathrm{C}$. The AREVA and GA teams maintained the prismatic block reactor design but also eliminated the IHXs and positioned a steam generator in the primary helium loop. The ratings of these plants reactor modules range from 350 to $625 \mathrm{MWth}$ with reactor outlet temperatures of $750^{\circ} \mathrm{C}$. Both of these reactor module configurations are targeted for supplying steam and electricity in co-generation applications and for extraction of bitumen from oil sands.

The end-users in the NGNP Industry Alliance consider that the first generation offering of the HTGR needs to also provide hot process gas (e.g., helium) at the highest practical temperature for use in existing applications that cannot be reasonably modified to use the cogenerated electricity and steam. It is the objective of the NGNP Project to continue to develop IHX technology and material development necessary to operate at the higher reactor outlet temperatures, (e.g., 900 to $950^{\circ} \mathrm{C}$ ).

To support engineering development of NGNP and to satisfy these requirements, several additional studies have been completed. These studies further developed specific design and operational requirements, developed and initiated implementation of technical risk reduction and management programs (including establishing programs to achieve the necessary technical readiness levels for developmental critical components), updated cost and schedule estimates for the NGNP Project and mature plant designs, evaluated the technical and economic viability of specific applications of the technology in the industrial sector, and supported development of white papers used in preapplication licensing discussions with the Nuclear Regulatory Commission (NRC).

The licensing and operation of NGNP will require the advancement and completion of a number of national standards and consensus codes that are used for design. The American Society of Mechanical Engineers (ASME), American Nuclear Society (ANS), and American Society for Testing and Materials (ASTM) have all been supportive of NGNP and have been involved with the standards and codes advancement activities. The ASME has developed a path forward for many of the code related issues in their Roadmap for the Development of ASME Code Rules for High Temperature Gas Reactors that is currently in draft form revision 8. This roadmap will be used to track the ASME Code Cases activities needed for codification of materials and material joining techniques at the elevated temperatures of the HTGR.

Development of the ASME Code Cases will require substantial research and technology development and the development of ASTM specifications. The general approach regarding materials is governed by the concept that any basic research that will support generation of new or revised ASTM specifications or standards will be managed by the NGNP Project R\&D organization. Generation or revision of higherlevel National Standards and Codes, such as the ASME Boiler \& Pressure Vessel Code, will be managed by NGNP Engineering. The NGNP Project team has positioned personnel in several key positions to advance codes and standards development in collaboration with national standard and consensus code organizations.

Although important engineering work has been completed by the NGNP Project, the development of the first-of-a-kind HTGR design has not progressed beyond the preconceptual stage. Limited progress in design and engineering is the result of suspension of design activities while DOE confirmed industry interest including the cost-share model to execute the NGNP Project. An interim step was taken by DOE in the early part of calendar 2010 to place a cooperative agreement with the General Atomics team derived from the Financial Offer of Assistance (FOA) issued in September 2009 to perform conceptual- 
level design work for the NGNP Project based on the prismatic block reactor concept. This work is scheduled to complete toward the end of calendar year 2010. DOE was not able to come to a similar agreement with a reactor supplier for conceptual-level design of a plant based on the pebble bed reactor concept. This results in a delay in developing the pebble bed based plant design.

There are a number of issues affecting the design of the HTGR plant that need to be addressed and resolved early in the design process, (e.g., during the initial phases of conceptual design). How these issues are resolved will affect the cost of the plant, the schedule for completion, the range of commercial applications to which the plant can be applied, the approach and scope of licensing by NRC, and the economics of the HTGR application. Work to date by the NGNP Project has addressed some of these issues on a generic basis without completion of conceptual design to anchor the analyses. Completion of this NGNP Project in a timeframe that is of interest and use to industry (e.g., initial plant operation in 2021 to 2022) requires that the final configurations and operating conditions for the plants be established and the issues listed herein begin to be addressed and resolved within FY 2010 and FY 2011. These are needed so that design, licensing, cost, schedule, and economic factors can be established with sufficient confidence to confirm HTGR design's technical, licensing, and economic viability. These include:

- Establishing the reference configuration, operating conditions, plant level analyses for the FOAK plant(s)

- Completing the design development studies identified in preconceptual design and follow-on work

- Completing the ASME/ASTM/ANS code case and standards development

- Defining the needs for infrastructure development and supply of equipment and materials, including:

- $\quad$ Large vessels

- Helium circulators

- Ceramics

- Heat exchange equipment

- Instrumentation and controls

- Valves.

- Developing the large scale component testing capability

- Developing and validating the capabilities of the high temperature hydrogen processes

- Improving cost and schedule estimate confidence levels

- Establishing limits on product contamination by radionuclides, particularly tritium

- Identifying, defining requirements, and resolving technical issues affecting co-location with industrial processes

- Identifying, defining requirements, and resolving technical issues affecting use of multiple modules.

The following section summarizes the results of developing and applying criteria that will provide the bases for selection of the reactor design to be developed further by the NGNP Project.

\subsection{Design Selection}

At the time of this writing, the DOE-Office of Nuclear Energy plan for conduct of the NGNP Project proposes to select the reactor design - pebble bed or prismatic - for further development based on a competitive down-selection process in 2011. The NGNP Project developed an assessment of the extent of technology development, design, and licensing maturity anticipated to be required to credibly identify differences that could make a technical choice practical between the prismatic and pebble bed reactor 
designs. This assessment was based on detailed comparison of these reactor designs in the following areas:

- Configuration, thermal rating and operating conditions, including comparison of over 30 specific design characteristics of two pebble bed reactor configurations and four prismatic reactor configurations that have been conceptualized as part of work completed to-date in the NGNP Project. This review included evaluation and assessment of differences of one design compared to the other in the following areas:

- Fuel composition, packing fraction, enrichment and burnup

- Core thermal fluid transport, including pressure drop, coolant flow, convective heat transfer, nonconvective heat transfer

- Core neutronics and fuel management, including refueling, excess reactivity, power peaking, analysis

- Graphite

- Instrumentation and control

- Source term

- Accident sequence

- Power output

- Proliferation.

- Technical viability to supply the several energy forms at the required conditions, (e.g., thermal rating, temperature, pressure) needed to supply the energy needs of the wide range of industrial processes identified to-date by the NGNP Project as candidates for application of the HTGR design.

- $\quad \mathrm{R} \& \mathrm{D}$ required to support design and licensing activities, including review of the objectives and coverage of the R\&D requirements of both reactor designs, including the fuel development and qualification, graphite development and qualification, high temperature materials qualification and the methods development and validation.

- Technology development required to complete design effort and to support licensing of the reactor concept by NRC. This comparison examined the summary of the design development needs identified in the NGNP Project for each reactor design in the Technology Development Roadmaps prepared as part of the NGNP Project Risk Management Plan.

The following conclusions were reached in this assessment:

- There currently is no substantive technical differentiation that could provide the basis for choosing a reactor design - whether pebble bed or prismatic. The conceptual-level design currently ongoing is not expected to change this conclusion.

- There currently is not sufficient confidence in the costs and plant economic evaluations performed to date to use these as differentiating factors, even if the business model were known.

- It is expected that the designs will need to be matured well into the preliminary design phase and the licensing basis matured to support impending submittal of a combined construction and operating licensing application before possible differentiating features will be identified. More specifically:

- The design of the systems and equipment will need to be sufficiently detailed to permit equipment sizing and layout and transient analyses to be completed

- The design of safety related systems and equipment will need to be sufficiently detailed to permit safety analyses, including accident frequencies and consequences to be determined 
- The fundamental licensing requirements will need to be defined through the preapplication process

- The industrial application to which the FOAK NGNP plant will be applied needs to be identified and the business case for this application needs to be developed.

- It is judged that sufficient technical differences will not be identified between the pebble bed and prismatic reactor concepts to make a selection for further development on a generic basis. In commercial application, the selection of which reactor design to apply is expected to be a function of the specific application, the licensing basis and the business case economics than the technical differences. These differentiators will require design maturation well into preliminary design to provide adequate confidence.

Advancement of the designs for both the pebble bed and prismatic reactor based plants through preliminary design is necessary. This design work needs to be complete enough to identify and complete the design of safety related structures, systems, and components (SSCs) and those important to safety sufficiently to support development of the COLA. To meet the schedule provisions of the EPAct this work needs to be completed in the 2013 time frame for submittal of the COLA in 2014. To achieve this level of design development in this time frame, DOE needs to engage now with industry and expedite the formation of the public-private partnership including development of the necessary strategic, schedule and cost sharing provisions. The work completed by the NGNP Project is sufficient to inform this development.

It is also the judgment of the NGNP Project that throughout the design and licensing process no differentiating technical factors will be identified that justify selection of one reactor design (i.e., pebble bed or prismatic) over the other. The selection of which reactor design should be made by the future owner of the plant based on specific licensing basis requirements and the business case. Potential end users and owners with whom the NGNP Project has discussed the application of this technology support developing two reactor plant designs (based on pebble bed and prismatic reactors) so they have a choice to better manage development risk, to promote competition and to provide flexibility in selecting the best alternative for the application and the business case. The implementation of parallel development paths has benefit to the NGNP Project by providing an alternative in the event major problems are encountered in one of the paths.

The NGNP Industry Alliance Limited, has proposed a NGNP Project Implementation Strategy that promotes development of the public-private partnership and proposes processes to ensure that both the government and the private sector perspectives are included in making major decisions on the paths forward for the NGNP Project. This strategy has an option to carry two plant designs to the point where a decision is to be made on building one or both plants. Under this approach, this decision would be made by the private sector which would then bear $100 \%$ of the cost for the final design, construction, and operation of the plant(s). This appropriately places the responsibility for this decision and the costs for the plant on the owner (s). Analysis of the projected costs for the DOE plan compared with the Alliance strategy shows very little difference in the costs to the government for either plan (Section 10 and INL/EXT-10-19566). The Industry Alliance and DOE should reconcile their recommended strategies and take the steps necessary for near term formation of the public-private partnership to provide both the government and the industry perspectives in directing and informing the future progress of the NGNP Project. Attachment 10 expands on the comparison of the DOE and Industry Alliance implementation plans.

\section{STATUS OF NGNP PROJECT R\&D ACTIVITIES}

At the inception of the NGNP Project, experts from DOE national laboratories, gas-cooled reactor vendors, and universities collaborated to establish technology R\&D roadmaps. These roadmaps outlined 
the testing and computational development activities needed to qualify the fuel and materials and validate the modeling and simulation tools to be used in the design and safe operation of NGNP, a helium-cooled HTGR. The technology development roadmaps draw on world-wide experience gained from the seven demonstration and/or prototype HTGRs that have been built and operated over the past 60 years. The roadmaps include detailed descriptions of the required technical activities with associated schedules and budgets for completion of the project and form the baseline for execution of the R\&D needed for the NGNP Project. The R\&D activities are organized into six major technical areas: (1) fuel development and qualification, (2) graphite qualification, (3) high temperature materials qualification, (4) design and safety methods validation, (5) heat transport and system integration; and (6) hydrogen production. Each of these activities is summarized in the following.

\subsection{Fuel Development and Qualification}

The objective of the Advanced Gas Reactor (AGR) fuel development and qualification program is to qualify TRISO-coated particle fuel and the production processes used to fabricate the fuel for use in HTGRs. TRISO-coated particles are used in both the pebble bed and prismatic reactor designs. As shown in Figures 6 and 7, the fuel particles are comprised of a fuel kernel made up of uranium dioxide for the pebble bed fuel and uranium oxycarbide in the reference designs ${ }^{\mathrm{c}}$ for the prismatic fuel surrounded by several layers of graphitic material that limits the transport of fission products from the fuel kernel. In the pebble bed reactor the fuel particles are distributed in a spherical graphite matrix - the so-called "pebble." The pebbles make up the core of the reactor and continuously travel through either cylindrical or annular paths through graphite reflectors. In the prismatic reactor the particles are distributed in cylindrical "compacts" that are stacked in cylindrical holes in prismatic blocks that in conjunction with prismatic graphite reflector blocks make up the reactor core.

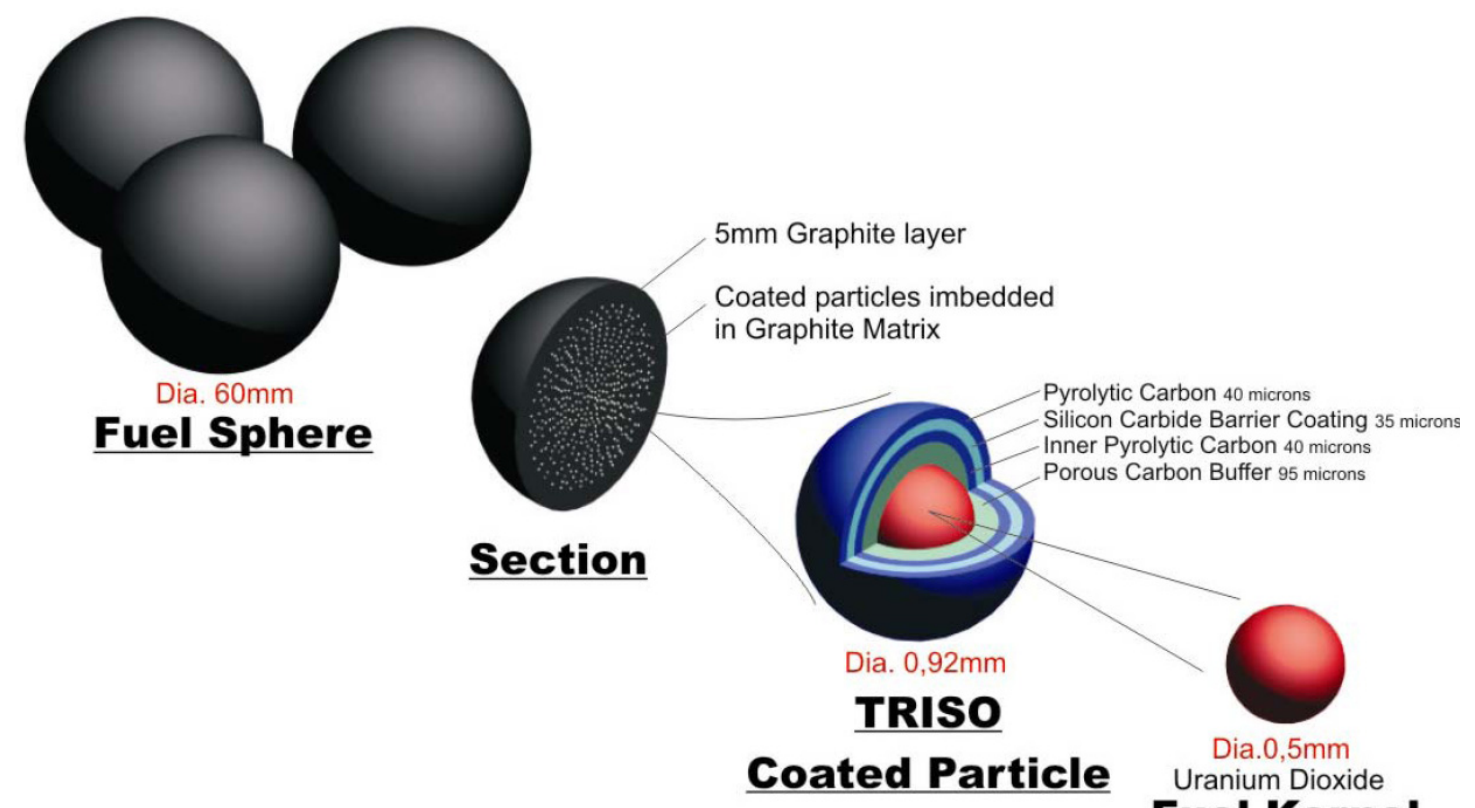

Figure 6. Pebble bed fuel element.

Fuel particles with uranium dioxide or uranium oxycarbide kernels can be used in either the pebble bed or prismatic reactor designs with appropriate changes to the neutronic design. Performance limitations may be encountered with the uranium dioxide kernels depending on the specific design. 


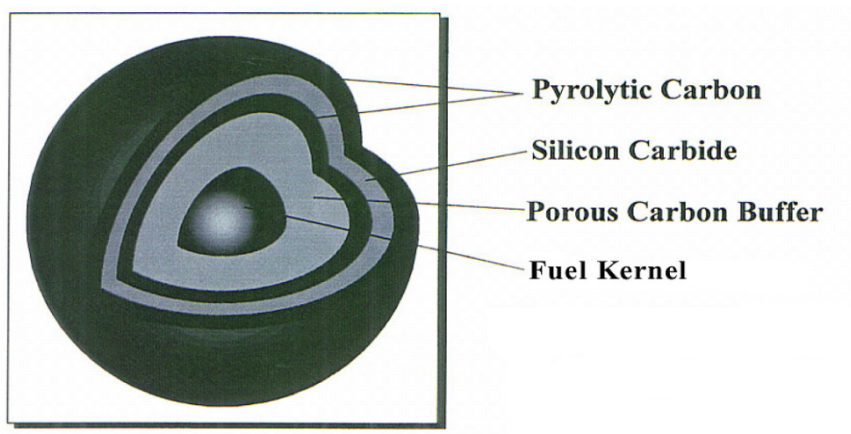

FUEL PARTICLE

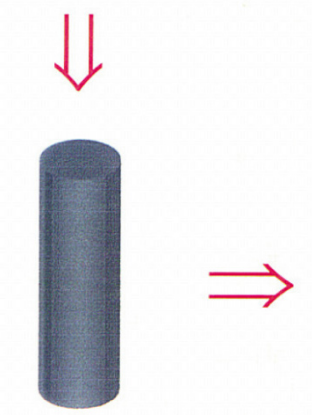

FUEL COMPACT

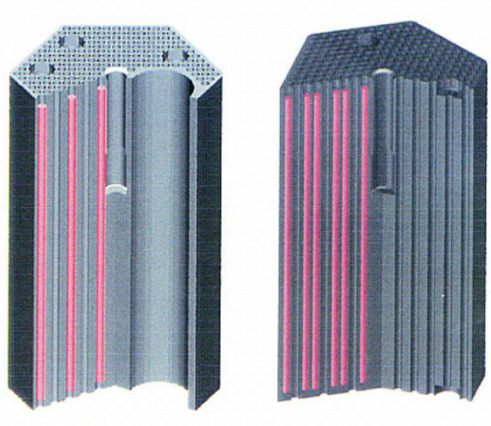

FUEL ASSEMBLIES

Figure 7. Prismatic reactor fuel particles, compacts and assemblies.

To-date fuel particles, pebbles, and compacts that are under test have been fabricated at a laboratory scale. To support commercialization of the HTGR design these must be fabricated at industrial scale and used in qualification testing. The NGNP Project is supporting establishing industrial scale facilities at Babcock \& Wilcox facilities in Lynchburg, VA and has formulated testing programs to complete this phase of qualification testing. The testing that has been completed and is planned consists of a variety of experiments and examinations that will allow an understanding of the behavior of TRISO-coated fuel under the extremes of the radiation and temperature environment expected in an HTGR. The program also contains experiments to provide an understanding of how the fission products - the elements produced when uranium fissions - are captured within the fuel or are transported through the fuel barriers into the primary helium circuit. Since the fuel particle is the primary barrier to release of fission products, these are important factors in establishing the source terms for this reactor design. Another important part of the program is the development of fuel performance and source-term modeling and simulation computer tools and the associated physical testing to validate those tools for use in the NGNP design and safety analysis.

\subsubsection{Fuel Manufacture}

At its inception, the AGR Fuel Development and Qualification program had to re-establish the capability to fabricate and characterize TRISO-coated particle fuel in the U.S. after about a decade-long hiatus. Many of the characterization procedures used in the past were still available but needed to be modernized to take advantage of current measurement technology. The result has been more controlled and reproducible fabrication and much more accurate and precise characterization of this fuel form. Systematic fabrication studies, combined with improved characterization capabilities, have also enhanced the understanding of how to fabricate high-quality TRISO fuel. The program is now fabricating highquality, low-defect (about 1 defect in every 100,000 particles), TRISO-coated fuel particles in an engineering-scale coater. 


\subsubsection{Fuel and Materials Irradiation}

The first irradiation test, AGR-1, recently completed approximately three years of irradiation. The fuel in AGR-1, composed of a reference fuel and three fuel variants having different inner pyrocarbon (IPyC) or SiC (silicon carbide) coating properties, was irradiated to a peak burnup of $19 \%$ FIMA, a peak fast-neutron fluence of about $4.5 \times 10^{25} \mathrm{n} / \mathrm{m}^{2}$, and a maximum time-averaged fuel temperature of about $1250^{\circ} \mathrm{C}$. About 300,000 TRISO fuel particles were irradiated without a single particle failure, as indicated by the fission-gas measurements on the purge gas from each of the capsules. These results are critical in demonstrating the superior performance capability of TRISO fuel and, ultimately, the modular HTGR concept.

The second irradiation, AGR-2, is underway. It contains both $\mathrm{UCO}$ and $\mathrm{UO}_{2}$ TRISO produced at industrial scale from U.S. and international collaborators (France and South Africa/PBMR). The UCO will be irradiated at prismatic conditions while the $\mathrm{UO}_{2}$ TRISO will experience conditions typical of a pebble bed HTGR. The third irradiation, AGR 3/4, is in final design, and the start of irradiation is scheduled for Fall 2011.

\subsubsection{Safety Testing and Post-Irradiation Examination}

This program element will provide the facilities and processes to measure the performance of TRISO fuel under normal operating and accident conditions. This work will support the fuel manufacture effort by providing feedback on the performance of kernels, coatings, and compacts. Data from PIE and simulated accident testing will supplement the in-reactor measurements as necessary to demonstrate compliance with fuel performance requirements and support the development and validation of computer codes.

\subsubsection{Fuel Performance Modeling}

Fuel performance modeling addresses the structural, thermal, and chemical processes that can lead to coated-particle failures. Physical models and computer programs will be developed and validated as necessary to support fuel fabrication process development and plant design and licensing.

New models are currently being developed in the U.S. that represent a first-principles-based mechanistic, integrated, thermal-mechanical-physio-chemical-irradiation performance model for particle fuel, which has the proper dimensionality yet captures the statistical nature and loading of the fuel. The INL PARFUME model has been extensively compared to similar tools developed by international colleagues as part of an effort under the auspices of the International Atomic Energy Agency. Successful benchmarking of the fuel performance model has resulted in NRC's desire to use the model as part of their activities in confirming the results from other simulations.

\subsubsection{Fission Product Transport and Source Term}

This element will address the transport to the environment of fission products produced within the coated particles to provide a technical basis for radiological source terms for HTGRs under normal and accident conditions. The fission-product behavior task will provide primary source-term data needed for licensing. The technical basis will be codified in design methods (computer models) validated by experimental data as necessary to support plant design and licensing.

\subsubsection{Fuel Acquisition Strategy}

A fuel acquisition strategy was established in 2007. In that report, detailed technical assessments of potential fuel vendors for the first core were conducted by an independent group of international experts 
based on input from the three major reactor vendor teams. While several credible options were identified, many of the assumptions underlying the strategy and externalities that have happened in the interim require that the options be re-evaluated once the preliminary design activities in Phase 2 are underway.

In terms of fuel testing, initial concepts for the configuration of AGR 5/6 qualification irradiation are being developed. While the concept developed in the original AGR program plan was based on prismatic UCO fuel to complement the large program that was underway and planned in South Africa, China, and Europe for $\mathrm{UO}_{2}$ pebble fuel, recent developments (shift of the program in Europe away from HTGR R\&D and lack of support for PBMR from the South African government) has required a re-assessment of options for the qualification tests, AGR-5/6.

\subsection{Graphite Data and Qualification}

In HTGRs, graphite physically contains the fuel and comprises the majority of the core volume. It also forms the inner and outer reflector (non-fueled) regions of the core. Graphite has been used effectively in the past as a structural and moderator material in both research and commercial HTGRs, establishing graphite as a viable structural material for high-temperature reactor cores.

However, while the general characteristics necessary for fabricating available graphite are understood, the specific performance of currently available nuclear-grade graphite at the anticipated operating conditions is unknown. Historical nuclear grades are no longer produced, and the raw feedstock material (e.g., petroleum and pitch coke) used to fabricate the graphite is no longer available from the sources historically used. Thus, the new graphite grades and associated fabrication processes must be qualified. The NGNP Project approach to qualification is consistent with historical assessments of graphite qualification needs identified by gas reactor vendors, NRC, and ASME. The approach also factors in international experience, particularly in the U.K. where the current incomplete understanding of in-pile graphite behavior in British gas-cooled reactors is causing the British utility to gather such data to respond to regulatory inquiries about the safety of those reactors in light of unexplained cracks found in graphite during reactor operation.

There is no irradiation experience with these new graphite types, so there is currently no way to quantitatively predict how they will actually perform within a reactor environment. While the graphite will be structurally stable for some period of time, the lifetime (as a function of dose and temperature) is not known for the current grades of graphite. This is a critical safety issue in that the stability of the graphite must be understood to determine the structural safety of the internal core. Therefore, the new graphite grades need to be characterized to demonstrate that they exhibit acceptable non-irradiated and irradiated thermo-mechanical and thermo-physical performance.

The program consists of statistical characterization of unirradiated graphite material properties to establish the lot-to-lot, billet-to-billet and within billet variability of the material. Irradiations are planned at specified temperatures and doses within the design service condition envelope anticipated for NGNP. Extensive post-irradiation examinations are planned to establish the change in relevant material properties as a function of temperature and neutron dose. Of particular interest is the irradiation induced creep of graphite, which is critical to determining the lifetime of the graphite under irradiation. From these datasets, constitutive relations will be established for use in a detailed predictive thermo-mechanical finite element model. These data will also support development of relevant ASTM standards and ASME design rules. In the longer term, the program plans to evaluate processing route and raw material constituent influences on graphite behavior so that additional large qualification irradiation programs are not needed when new coke sources are used to make graphite for HTGRs. 


\subsection{High-Temperature Materials Qualification}

The high outlet temperature of an HTGR, above $750^{\circ} \mathrm{C}$ depending on the application need, requires the development of high-performance metallic alloys to transfer heat from the reactor to the process application. Because these alloys will contain the high-pressure helium used to cool the reactor, stringent requirements are imposed to ensure that this piping and the equipment through which the helium flows, called the pressure boundary, will maintain its integrity. ASME assembles these requirements into code cases for use by designers to demonstrate structural adequacy. Today's high-temperature alloys and associated ASME codes for reactor applications are approved only up to $760^{\circ} \mathrm{C}$. Thus, the goal of hightemperature materials $\mathrm{R} \& \mathrm{D}$ is to obtain the performance data required to support the development of these high-temperature components and associated design codes over the broader range of envisioned outlet temperatures (up to $950^{\circ} \mathrm{C}$ ) for HTGRs.

The objective of the high-temperature materials R\&D program is to establish the relevant thermomechanical performance data to support the development of the high-temperature components operating between 750 to $900^{\circ} \mathrm{C}$. Creep, creep-fatigue, aging, and environmental degradation testing is planned using the candidate high-temperature nickel-based alloys such as Inconel-617 and Incoloy $(800 \mathrm{H})$. Constitutive models are also needed to describe the behavior of the alloy in tensile loading at elevated temperatures. Thick and thin sections of base material, weldments, and other joints such as diffusion bonding will be evaluated given the different design options under consideration for the IHX. Depending on the outlet temperature, additional high-temperature data may be needed to support relevant ASME code cases for the material.

The $R \& D$ required to establish requisite in-service inspection techniques will be developed as key components are designed. Prototype testing of key components is envisioned in a high-temperature flow loop to characterize overall behavior under prototypic HTGR flow conditions and to validate in-service inspection techniques.

\subsection{Design and Safety Methods Development and Validation}

An important activity in designing and licensing an HTGR is to confirm that the intended HTGR analysis tools can be used confidently to make technical decisions, ensure that reactor systems perform as required for the safety case, and meet the performance objectives of the design. The R\&D activities defined in the design methods development and validation program will ensure that the tools used to perform the required calculations and analyses can be trusted. The methods R\&D tasks are designed to ensure that the calculational envelope of the tools used to analyze HTGR reactor systems encompasses or is larger than the operational and transient envelope of the HTGR itself.

The methods R\&D area focuses on the development of tools to assess the neutronic and thermal fluid behavior of the plant. The fuel behavior and fission-product transport models are part of the TRISO fuel development program.

The goal of the design and safety methods validation program is to develop experiments and data to validate models and analytical tools for the HTGR. As part of the effort, the program will resolve key safety, performance, and technical issues through confirmatory modeling and/or develop new tools when existing models and/or tools are judged inconclusive or inadequate. This will be accomplished in the near term via separate effects testing, benchmarking, and developmental assessment. In the longer term, software tools will be validated using data from large-scaled integral experiments. This work will reduce uncertainties and improve the capability of understanding the behavior and operating margins of HTGRs. 


\subsection{Heat Transport and System Integration}

Economic substitution of reactors for fossil fuels in conventional processes requires integrated, efficient heat-transport systems to utilize the reactor's heat. The purpose of these activities is to analyze potential processes when coupled to a gas-cooled reactor, based on technical merit, emissions reductions, economic parameters such as product costs, and contribution to improving energy security. Development and demonstration of the components and systems needed to deploy the most promising processes will be complete when they progress to the technical maturity needed to predict successful deployment at commercial scale. The required technology maturity includes the following.

- Establish and model heat transport and process configurations: this modeling is conducted based on thermal, chemical, and physics models that determine the technical aspects of heat transport and systems integration viability, as well as the systems-level models looking at the overall products of the processes, their potential economic and environmental impacts, and the business model(s) associated with HTGRs providing process heat, electricity, and other products to an end user.

- Optimize heat transport and process configurations.

- Technology development studies: this development area explores the development of the primary components of the heat transport system, including (1) heat transfer from the reactor core to a primary heat exchanger, (2) secondary heat transport (via helium or steam as close-to-market applications and other fluids for potential process applications), and (3) use of the heat in the industrial processes. Technology development efforts are needed for each subsystem.

- Create component and pilot-scale testing infrastructure.

Component and pilot-scale demonstration and validation: Bench, experimental, and pilot-scale tests are needed to evaluate single-effects and integrated system performance of new process-specific heat exchangers, components, and technologies.

\subsection{Hydrogen Production}

Essentially carbon-free production of hydrogen can be achieved by high temperature disassociation of water as an alternative to using natural gas as a feedstock and the source of heat for steam methane reforming. This capability can potentially play a key role in decreasing future petroleum imports, relieving the pressure on U.S. natural gas supplies and reducing emissions from production of hydrogen and transportation fuels. Beyond the need for process heat, hydrogen is a vital feedstock in the production of ammonia, upgrading of low-grade petroleum, and the production of synthetic transportation fuels, all potential end users for HTGR energy.

High temperature electrolysis was recently selected by DOE as the hydrogen generation design of choice following recommendations by an independent review team for further development based on its maturity and ease of integration with nuclear systems. The review team also recommended that high temperature electrolysis R\&D: "(1) refine the understanding of cell/stack degradation modes and mechanisms, and (2) demonstrate pressurized cell/stack operation at a laboratory scale." The review team also recommended evaluation of other alternative cell and stack designs. The path forward follows these recommendations and addresses the following issues:

- Improvements in cell performance

- Development of larger cells

- Pressurized operation

- Improved scientific understanding of electrolytic operation. 


\subsection{International Collaboration}

Much of the R\&D being performed for NGNP is being offered under the Generation IV International Forum multilateral collaboration auspices. NGNP R\&D staff are actively engaged in Project Management Boards (the collaboration vehicle) in the areas of (a) fuel and fuel cycle, (b) materials (both metals and graphite), (c) computational methods; and (d) hydrogen. Under this multilateral framework, R\&D being done in Europe, Asia, and South Africa is available to DOE and the NGNP Project, offsetting some of the needed technology development for NGNP and supplementing the near term NGNP R\&D with longer term technology development for the High Temperature Reactor. Examples are provided in Attachment tab 4, Research and Development Status, to this report.

A bi-lateral collaboration exists with the High Temperature Test Reactor (HTTR) in Japan (and a parallel collaboration is planned for HTR-10 in China) to obtain unique operational data from an operating pebble bed and prismatic reactor. For example, testing has been conducted at HTTR to measure tritium permeation through the heat transport equipment as a function of outlet temperature (between 800 and $\left.950^{\circ} \mathrm{C}\right)$.

Specific examples of important data sharing include irradiation data, materials property data from

fuels, graphite irradiation response data, creep characterization and creep fatigue behavior analysis, as well as welding and stress relief practices. 


\section{NGNP PROJECT LICENSING APPROACH}

As mandated by The EPAct, the NGNP Project has developed and begun to implement a licensing strategy for the Next Generation Nuclear Plant. The centerpiece of the NGNP licensing strategy is the development of a combined license application (COLA) pursuant to 10 CFR 52. To do this, the NGNP Project and NRC must agree on COLA content requirements and the guidance documents suitable for the NGNP. Furthermore, the NGNP design must be developed to the point where sufficient information is available to complete the COLA and assure NRC acceptance for review.

The NGNP Licensing Plan (PLN-3202, June 26, 2009) describes a strategy that will support NGNP licensing and future commercial applicants. The plan focuses on the most significant policy issues for resolution during initial NRC interactions and outlines a licensing path that will lead to approval of a COLA by the NRC.

\subsection{Preapplication Discussions}

The plan currently emphasizes performance of critical preapplication licensing activities that will proceed in parallel with the DOE's establishment of a public-private partnership for NGNP deployment. Important issues proposed for early preapplication discussion with NRC were derived from a number of industry sources and prioritized on the basis of their expected impact to plant design, licensing, and overall project completion. The effort identified 35 high-priority technical and policy issues essential to enabling project execution. The issues being addressed at the time of this writing include:

- Implementation of risk-informed, performance-based methods that utilized inputs from probabilistic risk assessments

- Selection of licensing basis events

- Defense-in-depth

- Safety classification of SSCs

- Emergency planning zone reduction and associated emergency action levels

- Regulatory concerns related to the co-location of HTGRs at industrial sites

- Mechanistic source terms, fission product transport, and containment functionality

- Fuel qualification

- Analytical code verification and validation

- High temperature materials performance

- Applicable codes and standards

- Air and water ingress.

After the partnership is established, the facility owner and/or operator within that partnership will become responsible for acquiring the facility license.

\subsection{CFR 52 COLA Content Guide and Preparation}

The plan identifies activities that support issuance of a COLA in accordance with 10 CFR 52 requirements. It calls for implementing a risk-informed and performance-based licensing approach and builds on previous licensing efforts and NRC interactions associated with gas-cooled reactor design. It also identifies the earliest and highest priority preapplication issues to be addressed in the preapplication 
period, independent of the design selected, the site where this design is to be located, and whether or not an Early Site Permit is submitted. The plan establishes, in two distinct phases, the regulatory basis and proposed COLA content for licensing of the NGNP by the NRC.

The NGNP Project will also assist NRC in the development of a COLA Content Guide, which prescribes the requirements for an HTGR final safety analysis report (FSAR). The new COLA Content Guide will provide format and content guidance, insights and lessons learned, and an initial applicability assessment for regulatory acceptance criteria of a HTGR within the current NRC LWR Standard Review Plan structure. This guide will serve to define engineering and other technical work products needed to support writing of the COLA.

There are two key sources of input for the COLA Content Guide. The first will come from the positions and strategies developed in NGNP licensing white papers that are submitted to the NRC staff early in the prelicense application period. The highest priority items were identified based on the potential for significant impact on the plant design and/or planned R\&D activities, and the likelihood that NRC action will be required to address the issue. The white papers that the NGNP Project has or is in the process of submitting to the NRC include Defense-in-Depth, High Temperature Materials, Mechanistic Source Terms, Fuel Qualification, Licensing Basis Events, and SSC Classification. The second source of input for the COLA Content Guide is development of a regulatory gap analysis, which defines the specific gaps between NRC's existing LWR regulations and guidance, and those that are needed for the evaluation and licensing of HTGRs. This input is considered critical because the existing LWR regulatory framework can only be partially applied to the NGNP HTGR design. Performance of the gap analysis, using a procedure already written for this purpose, is planned to commence in the fourth quarter of FY 2010 and finish in mid-FY 2011.

The COLA will contain an FSAR that describes the facility, presents the design bases and limits on operation, and presents a safety analysis of the facility as a whole. The FSAR will include information at a level sufficient to enable the NRC to reach a final conclusion on all safety matters before a COLA will be submitted. The NGNP COLA is expected to be comprised of up to 11 parts, supplemented by various topical reports. A topical report is an administrative tool used to establish a technical basis in a particular topic area to support a pending licensing action. Topical reports are submitted individually to the NRC and form the basis for a portion of the overall COLA. Preliminary evaluations of the HTGR COLA suggest that 100 to 150 topical reports will likely be included as a part of the first HTGR application. Since topical reports are intended to bring regulatory finality to a specific subject, they have their greatest benefit when they are made available to the NRC early in the licensing process. Issues that lend themselves to topical reports include the High Temperature Test Reactor tritium study, composites study, contamination control study, air and water ingress analysis, multiple module integrated risks, containment functionality, fuel qualification, graphite and material qualification, qualification of radionuclide transport barrier decontamination factors, and the probabilistic risk assessment basis.

\subsection{Phased Approach}

Many preapplication items identified in the NGNP Licensing Plan will require significantly more details than can be supported by a conceptual plant design. Certain plant configurations may not be available until the initial license application is developed by the facility owner/operator. These specific design details will continue to be developed as the overall project progresses and associated public-private partnership(s) are formed. Therefore, near term NGNP licensing efforts will continue to focus on priority topics that can be developed and addressed with the available design detail and lay the groundwork for addressing the more design-driven preapplication topics (Phase 1 as shown in Figure 8). Essential elements of current plant development and licensing efforts include establishing Top Level Radiological Requirements for the plant, (e.g., setting dose limits at the exclusion area boundary) that reduce emergency planning requirements and support close co-location of the HTGR with an industrial facility. 


\section{Overall Sequence}

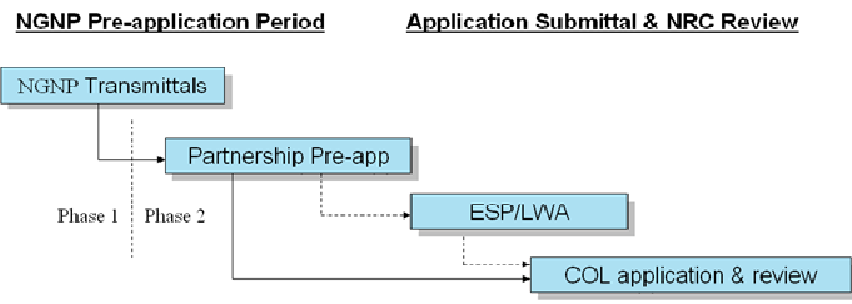

Figure 8. Phased approach sequence.
It also includes development and understanding of the radiological source term based primarily on fuel design, qualification testing results, and analytical method development, as well as prevention and mitigation of source term releases to the environment that includes defining licensing basis events and establishing multiple release barriers consistent with a defense-in-depth strategy. Also important is the development of an updated emergency planning structure that considers potential radiological releases

coupled with various industrial application configurations to ensure the protection of public health and safety in the unlikely event of a radiological release.

Phase 2 of the NGNP Project will proceed with the development of the partnership, identification of the owner and operator of the plant, selection of the design and final design activities. Development and submittal of the ESP/LWA and COLA for the plant can then be completed.

Proceeding through the licensing sequence summarized in this report will result in a more predictable and well-understood licensing path forward for the NGNP Project, with significantly reduced regulatory uncertainty for HTGR licensing. Key to this process is the regular and continued interaction with the NRC Staff as HTGR policy and technical issues are addressed and resolved. These resolutions must then be reflected in the jointly developed HTGR COLA Content Guide. NGNP Project licensing activities intend to continue on this path to the point where licensing activities can be transitioned to the COLA applicant.

At the time of COL application, it is likely that certain policy and technical issues will still be in the evaluation and resolution process between the project and NRC due to the time necessary to address various issues (items that require completion of multi-year confirmatory research programs, NRC policy issue dispositions that are being promulgated through the required regulatory document processes, etc.). Therefore, it is expected that certain portions of the COL application will not be fully populated and complete at the time of application submittal. The NGNP project team intends to clearly identify these areas and their associated resolution paths as a part of the application process, so that NRC docketing and application review can proceed, while the remaining portions of the application content are being finalized. 


\section{STATUS OF NGNP PROJECT RISK MANAGEMENT PROGRAM}

Throughout the NGNP Project life cycle, technical risks are identified, analyzed, and mitigated and decisions are made regarding the design and selection of plant and sub-system configurations, components and their fabrication materials, and operating conditions. Risk resolution and decision making are key elements that help achieve project completion within budget and schedule constraints and desired plant availability. To achieve this objective, a formal decision-making and risk management process was developed for NGNP, based on proven systems engineering principles that have guided aerospace and military applications.

NGNP Project risk management follows INL and U.S. DOE guidelines and includes the identification, impact assessment, and prioritization of technical and programmatic risks followed by a coordinated application of resources to mitigate or eliminate risks that may impact the successful outcome of the NGNP Project. This requires that: (1) technical and programmatic risks be identified, quantified, and mitigated, as appropriate; and (2) risk mitigation strategies be developed, documented, and implemented. The risk methodology developed and applied for the NGNP Project included systems for reporting and tracking risks, risk status, and risk resolution. Risk management will enhance the probability of NGNP Project success by improving project performance and decreasing the likelihood of cost overruns, schedule delays, and potential compromises in quality, which are often caused by reliance on immature technologies.

A Technology Readiness Assessment was conducted to estimate the maturity of systems and components and further understand the risk associated with their design, manufacture, and operational performance. Through this assessment, the technical maturity baseline shown in Figure 9 was established using scales called Technology Readiness Levels (TRL). TRL ratings for NGNP: (1) are on a scale of 1 to 10 ; (2) use the current development state of proposed technologies as their starting points; and (3) provide a consistent measure of readiness and confidence in the SSCs ability to reliably perform its function. The TRLs serve as a measure to integrate $R \& D$ activities with the necessary design and licensing activities anticipated for the NGNP.

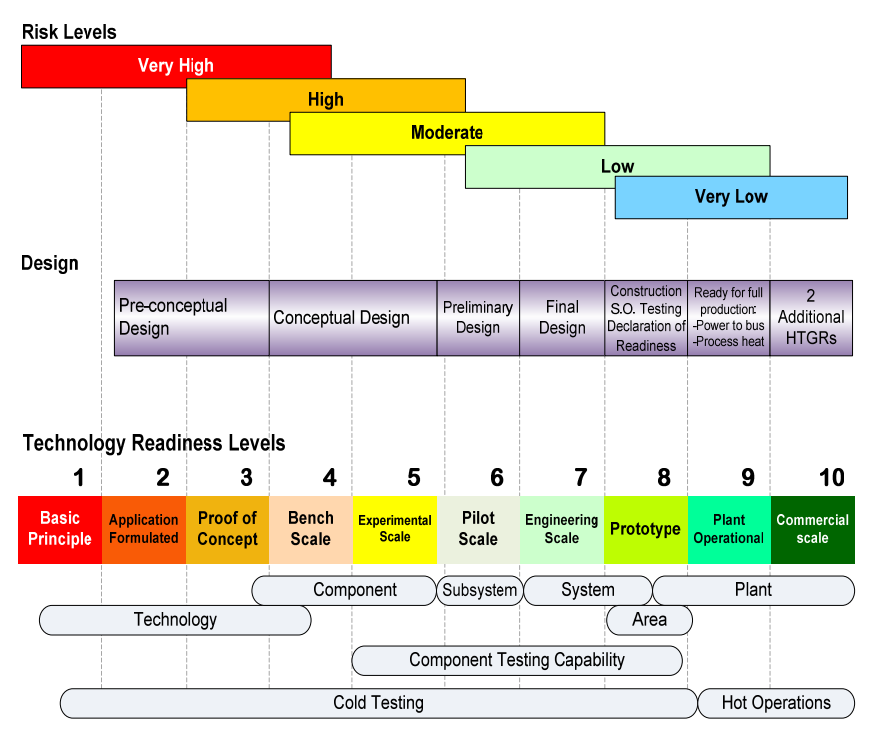

Figure 9. Technical maturity baseline.

With the baseline critical SSCs and their associated TRLs defined, experts from DOE national laboratories and gas-cooled reactor vendors established technology development "roadmaps" and developed the documents that outlined the licensing, engineering design and R\&D activities required to guide the technology maturation process. Roadmaps set the project course for design selection and qualification, and for the integration of developing components into mature and operable systems.

The roadmaps include detailed descriptions of the required technical activities, with associated schedules and budgets for project completion, as well as the integration of needed research, development, and qualification activities. The roadmap identifies: (1) key selection discriminators; (2) key technology decision points and the scientific and technical information necessary to make informed technology 
selections; (3) current TRL assessments; (4) development tasks needed to mature technologies; and (5) test plans to advance TRL assessments for components and systems. Roadmaps facilitate the ability of the project to successfully meet scheduling and budgeting demands. To support project management, technology roadmaps: (1) align short-term and long-term goals and identify the technology development activities needed to meet those goals; (2) focus resources on critical technologies; (3) provide early identification and management of technical and programmatic risks; and (4) ensure technology readiness is demonstrated through testing, modeling, piloting, and prototyping.

The technology development activities of the NGNP Project are in concert with the technology development roadmaps and, therefore, are targeted to deliver the necessary information to resolve Design Data Needs, technical issues as identified in the NRC Phenomena Identification and Ranking Tables, as well as ASME codification needs, culminating in the information required to be submitted as part of the Combined License Application. All of these deliveries reduce the risk to the NGNP Project and help ensure timely, quality delivery of information to reduce uncertainty in overall project schedule and cost. 


\section{THE HTGR POTENTIAL MARKET AND PRELIMINARY ECONOMICS}

The NGNP Project is developing the HTGR design to supply high temperature process heat to industrial processes as a substitute for burning of premium fossil fuels, such as natural gas. Commercial applications for HTGR design that have been evaluated by the NGNP Project include electricity generation, supply of electricity, steam and high-temperature gas to a wide range of industrial processes, and production of industrial gases (i.e., hydrogen and oxygen) for use in petrochemical, refining, coal to liquid fuels, chemical, and fertilizer plants. As a non- $\mathrm{CO}_{2}$ emitting substitute for the burning of fossil fuels, the HTGR can offset significant quantities of industry-generated $\mathrm{CO}_{2}$ emissions. The use of the HTGR design as a "feedstock substitute" for natural gas (e.g., production of hydrogen by disassociation of water) in many of these applications and for conversion of coal to synthetic fuels and chemical process feedstock improves the security of the U.S. energy supply by reducing reliance on imports, reducing energy price volatility that has been experienced over the last few decades (e.g., wide swings in the prices of oil, natural gas and coal), and extending the life of non-renewable energy resources for use within more productive and efficient applications where no current alternatives are available.

Market studies have identified a large potential commercial market for the HTGR design. The highest priority markets include natural gas and coal derivatives, (e.g., petrochemical production, synthetic transportation fuel production), hydrogen production, ammonia and ammonia derivatives (e.g., fertilizer), metals production, petroleum refining and enhanced oil recovery, (e.g., from oil sands and oil shale). Technical evaluations have been completed to show the viability of integrating the HTGR design with conventional and modified processes in these market sectors. Trade studies have shown the potential for integration of HTGR design in conventional processes for supply of steam, electricity and high temperature gas in co-generation applications, for production of hydrogen, and for the use of hydrogen in production of gasoline in methanol to gasoline processes, production of diesel fuel in coal and biomass to liquid fuel conversion processes and synthesis of ammonia.

The higher operating temperatures of the HTGR result in net thermal efficiency in electric power production comparable to natural gas and coal plants. This makes use of the HTGR design a practical substitute for fossil fired plants, particularly in areas with low cooling water availability or limited transmission and distribution capacity that would otherwise be unable to take advantage of nuclear energy produced by LWRs. This is a potentially very significant market.

These evaluations of the potential market and preliminary economics provide a foundation for making decisions on technical requirements for the HTGR module designs as the NGNP Project moves forward. The overall functional and performance requirements derived from these studies provide the basis for detailed design specifications to be developed by the nuclear systems suppliers in cooperation with the future HTGR plant owners. In contrast to LWRs for electric power generation, it is anticipated that as the high temperature process heat and related markets mature, and the owners step forward to invest, a spectrum of designs will emerge that best fit each market. A primary objective of the NGNP Project is to envelop the most important of these functional and performance requirements in its supporting development work, and in selecting a representative FOAK application that provides a demonstration useable to the broadest possible future market.

A typical HTGR based plant in an industrial application will comprise multiple HTGR modules; each module with a rating between $200 \mathrm{MWth}$ (megawatt thermal) to $600 \mathrm{MWth}$. A typical plant would have a total rating of 2,000 to 2,400 MWth (4 to 10 modules) with some plants at much higher ratings, (e.g., coal to liquids plant). 
To the time of this writing the assessments of the potential markets and discussions with end users have been focused on understanding the full energy needs of the targeted industries to inform the design requirements of the HTGR to meet these needs. As cited above, the targeted markets include established industries, such as the co-generation, bitumen extraction from oil sands and hydrogen production, while the conversion of coal to synthetic fuels and feedstock will be a new market in the U.S. whose development would be enhanced through application of the HTGR design.

For the purposes of providing a basis for quantifying the benefits of use of the HTGR design in these applications, the NGNP Project has assumed certain levels of penetration of these markets based on engineering judgment. The results and conclusions of the assessments of these levels of penetration can be summarized as follows:

- Deployment of 421,200 MWth of HTGR design (827 reactor modules rated at about $600 \mathrm{MWth}$ ) in the time frame 2020 through 2050 . This deployment providing steam, electricity and high temperature gas to the process heat market, providing steam and hydrogen for bitumen recovery and upgrading from oil sands, producing hydrogen for the merchant market, produce synthetic fuels and feedstock from coal and biomass and supplying non-GHG emitting electrical power to the national grid.

- Reduce import of crude oil $\sim 2.4$ million barrels per day ( $25 \%$ of the imported oil in 2009 ); replacing the equivalent in crude oil based gasoline and diesel fuels with synthetic transportation fuels and feedstock produced from coal

- Implement a beneficial and efficient use of coal by conversion to synthetic fuels and chemical feedstocks without generating GHG emissions

- Reduce $\sim 6.7$ trillion cubic feet of natural gas consumption in the U.S, per annum

- Reduce $\mathrm{CO}_{2}$ emissions by $\sim 390$ million metric tons per annum ( $7 \%$ of the total $\mathrm{CO}_{2}$ emissions in the U.S.).

As noted, the penetration of the markets for which these apply are based on engineering judgment. More detailed market studies are required to develop confidence in market size and penetration and the associated benefits. Section 8 and INL/EXT 10-19037 provides a broader assumed deployment of the HTGR design as part of a broader transformation of the U.S. energy infrastructure with a detailed summary of the benefits attendant to that deployment.

Preliminary business models have been formulated and preliminary economic evaluations of these business models have been performed to assess the economic viability of these applications (see Figure 10). These business models address the fundamental differences in the economics of a nuclear plant which are sensitive to capital recovery, with a fossil fired plant, (e.g., natural gas) whose economics are driven primarily by fuel costs. These business models also address at a preliminary level the potential differences in the economic criteria and financial parameters that apply to ownership of a nuclear plant versus that of a conventional industrial plant. They also provide flexibility in addressing varying scenarios of nuclear plant and industrial process ownership and operation.

These evaluations show that the HTGR design can be competitive with traditional fossil fired processes depending on the assumptions of capital and operating costs, financing and the potential for governmental policies to put a cost on carbon emissions in the future. As an example, Figure 10 shows the price of steam supplied by an HTGR based co-generation plant compared with a comparable combined cycle gas-turbine plant with variations in the price of natural gas and a potential cost of $\mathrm{CO}_{2}$ emissions. However, the real impact of the economic evaluations on the viability of the HTGR design is not easily addressed generically. The end user of the energy produced by this design may consider the long term benefits of the design such as security and stability in the price of energy and feedstock an important shelter from the potential costs of carbon emissions sufficient to justify a higher initial cost. 
How to account for this fact is being pursued with the end users and other stakeholders in development of the HTGR design.

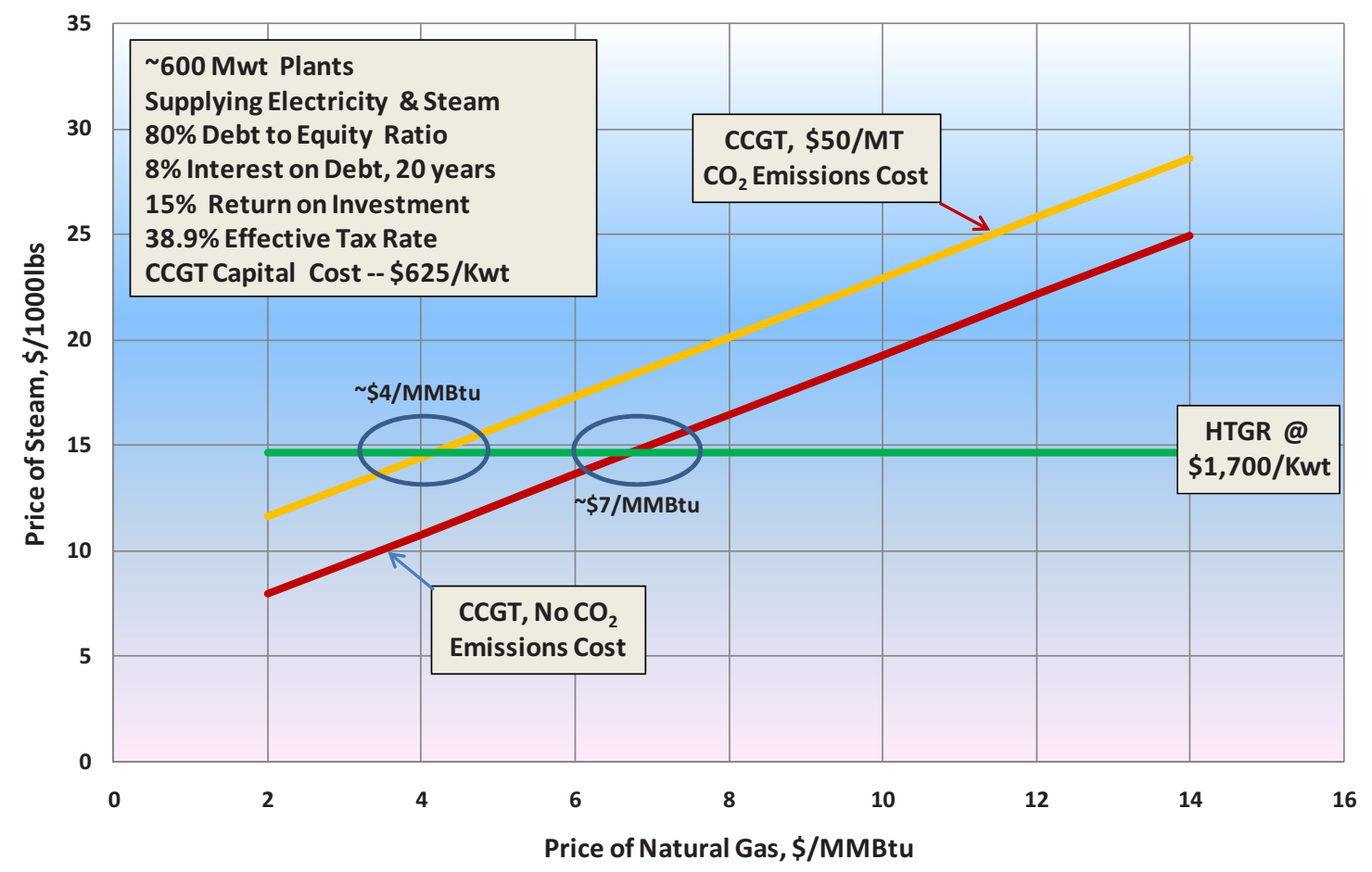

Figure 10. Price of steam generated by an HTGR and a CCGT vs. the price of natural gas and cost of GHG emissions.

Because of the preconceptual phase of development of the HTGR design there is large uncertainty in the capital and operating costs of the HTGR plant and, therefore, comparably large uncertainty in the results of the economic evaluations. To develop confidence in the technical and economic viability of the HTGR design, the designs of the plants need to be progressed beyond their current preconceptual status to provide better estimates of performance and costs to construct and operate. The economic factors for financing and pricing of energy over the long operating lifetime of the HTGR plants need to be refined through discussion with major financial institutions with an energy portfolio, current nuclear plant owners and major industrial plants that can benefit from use of energy supplied from the HTGR. As the designs of the HTGR plants mature, better estimates of the capital and operating costs for these plants will be developed supporting higher confidence levels in the results of the economic models. This will in turn improve the confidence in the continuing evaluations of the technical and long term economic viability of the HTGR applications. 


\section{A TECHNOLOGY-BASED STRATEGY FOR TRANSFORMING THE U.S. ENERGY INFRASTRUCTURE}

Separate from the preceding market-based assessment, the NGNP Project assessed alternatives and developed a strategy to effect potential changes in the way in which energy is produced and consumed in the U.S. to address negative aspects of the U.S. energy infrastructure. Although the U.S. energy infrastructure is among the most reliable, accessible and economic in the world, it relies heavily on foreign sources of energy, experiences high volatility in energy prices, does not practice good stewardship of finite indigenous energy resources and emits significant quantities of GHG. The NGNP Project strategy addresses these aspects by reducing GHG emissions and price volatility, improving energy security and addressing resource stewardship on a straightforward and permanent basis using U.S. technology and industrial infrastructure. The detailed summary and basis for this strategy- the so-called Technology Based Strategy - is the subject of the paper provided in Attachment tab 8, Transforming the U.S. Energy Infrastructure, to this report.

A realistic approach to establishing a strategy for transforming the energy infrastructure requires maximizing flexibility as components of national energy policy change, energy economics change, and energy technologies advance. A common theme that should be considered is ensuring that options exist in energy production and use that can address changing needs. However, these type options can take one to two decades to commercialize - and are hence beyond the practical reach of typical private sector business investment, thus requiring support of government through government-industry partnerships.

The strategy developed by the NGNP Project is based on contemporary policies, (e.g., ARRA) and what appear to be emerging policies, (e.g., pending legislation such as HR 2454, S1733). It is also based on minimizing the risk of technology development required to achieve the objectives of this strategy. Whereas higher risk technologies are described and applied at a level consistent with its risk level, lower risk technologies are used for drawing conclusions for fulfilling the objectives for the policies being considered.

The strategy attacks the vulnerabilities of the energy infrastructure by first addressing the GHG emissions reduction objectives developed by policy papers of the Administration and being codified in Congressional pending legislation. Figure 11a depicts the DOE Energy Information Administration summary of current and projected $\mathrm{CO}_{2}$ emissions through 2050 by emission source; electricity production, coal burning, natural gas burning and transportation, primarily combustion of gasoline and diesel fuels. Figure 12 shows the rate of reduction per annum and the total reductions that are required to meet the full emission reduction objectives of the Administration and Congress ( $\sim 5,640 \mathrm{Mt}$ below projections in 2050). The data are shown in million metric tons of $\mathrm{CO}_{2}$ emitted per annum; shortened to Mt for convenience. It is clear from review of these two figures that there is no one area that can be targeted to achieve the objectives. All GHG emitting sectors must be addressed.

The Figure 13 shows the results of applying the Technology Based Strategy to emissions reductions. A five prong approach has been developed using available or in development technology. 


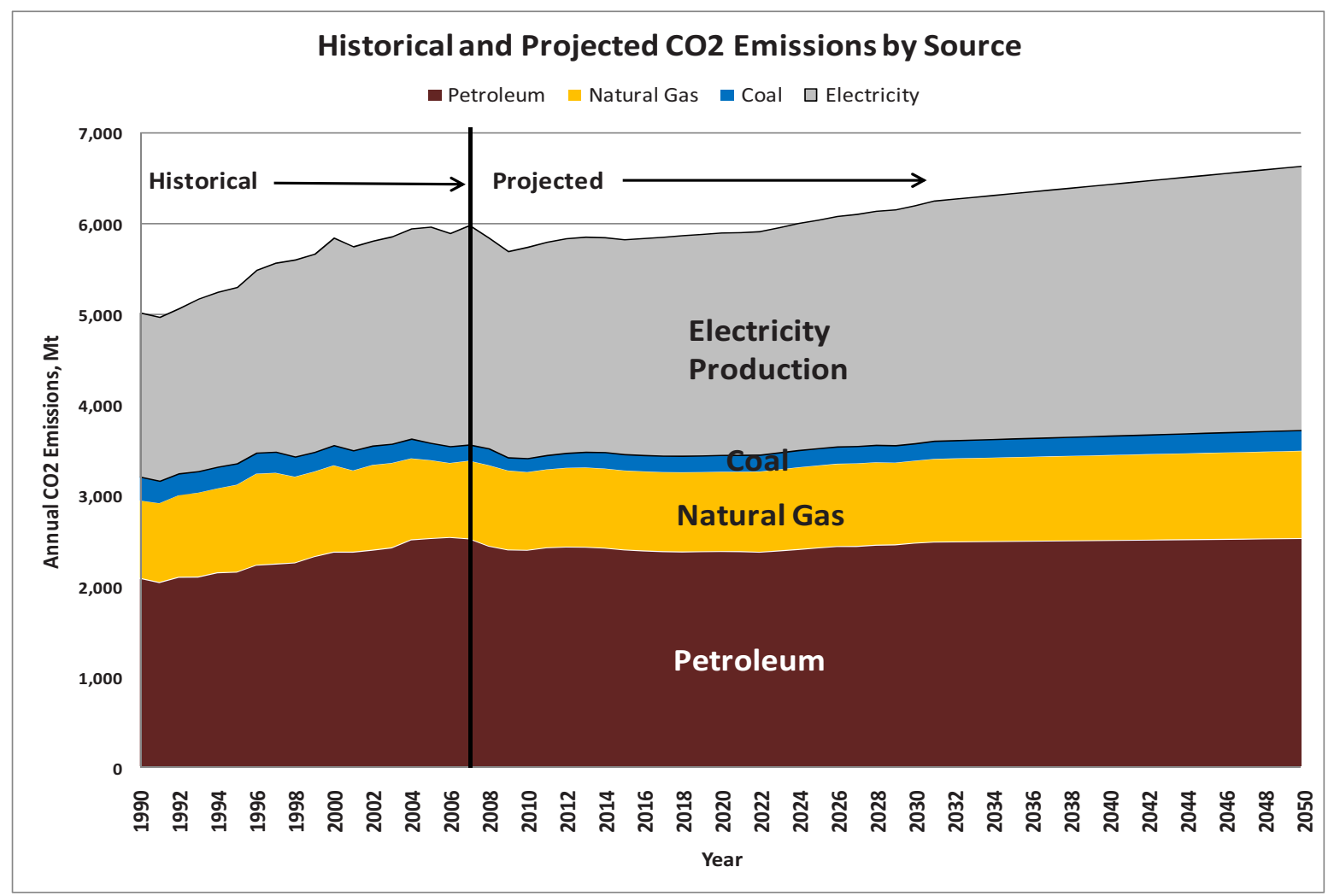

Figure 11. DOE/EIA Summary of Historical and Projected $\mathrm{CO}_{2}$ Emissions by Energy Source.

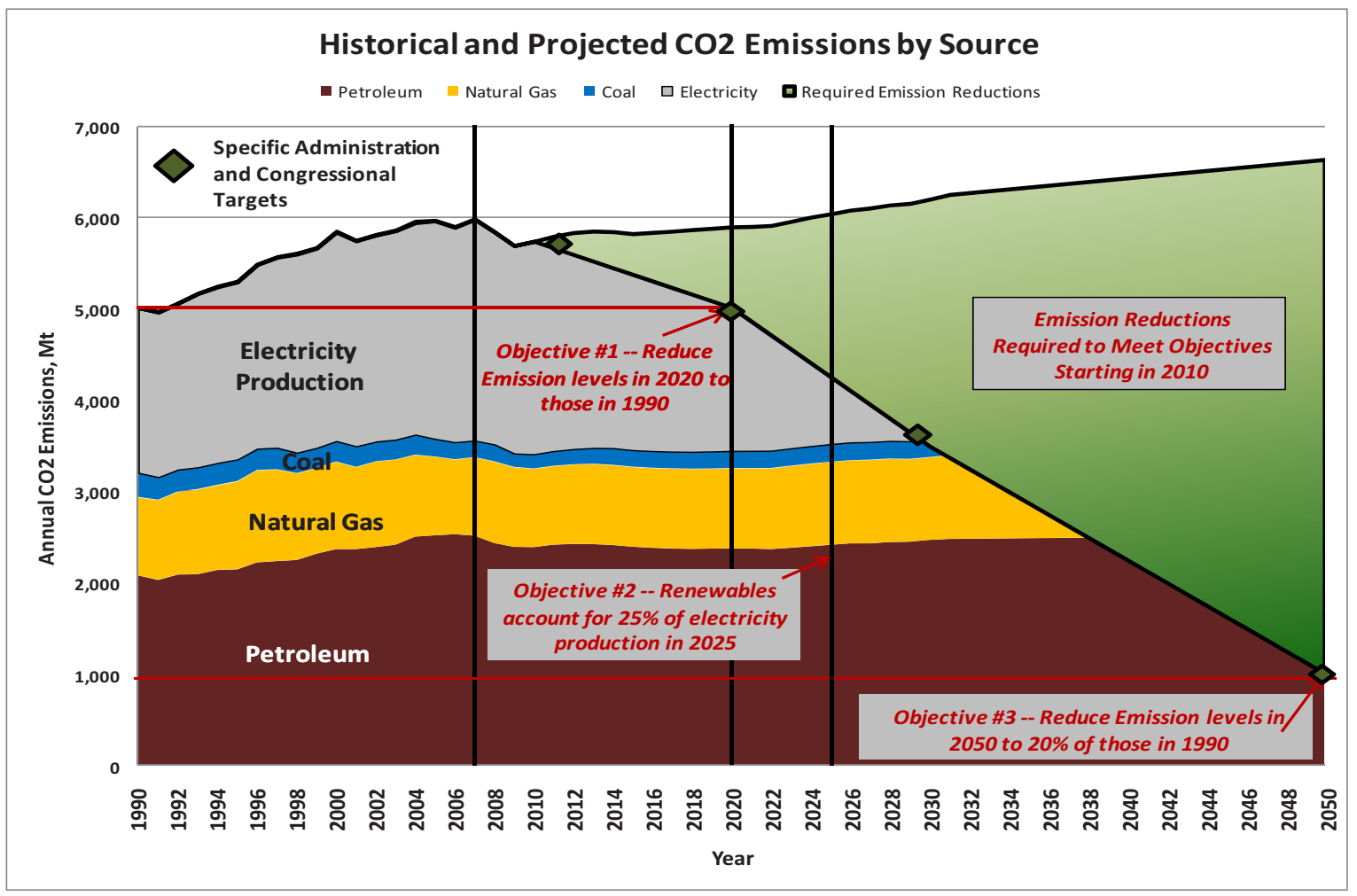

Figure 12. Reduction in $\mathrm{CO}_{2}$ emissions required to meet administration and congressional targets. 


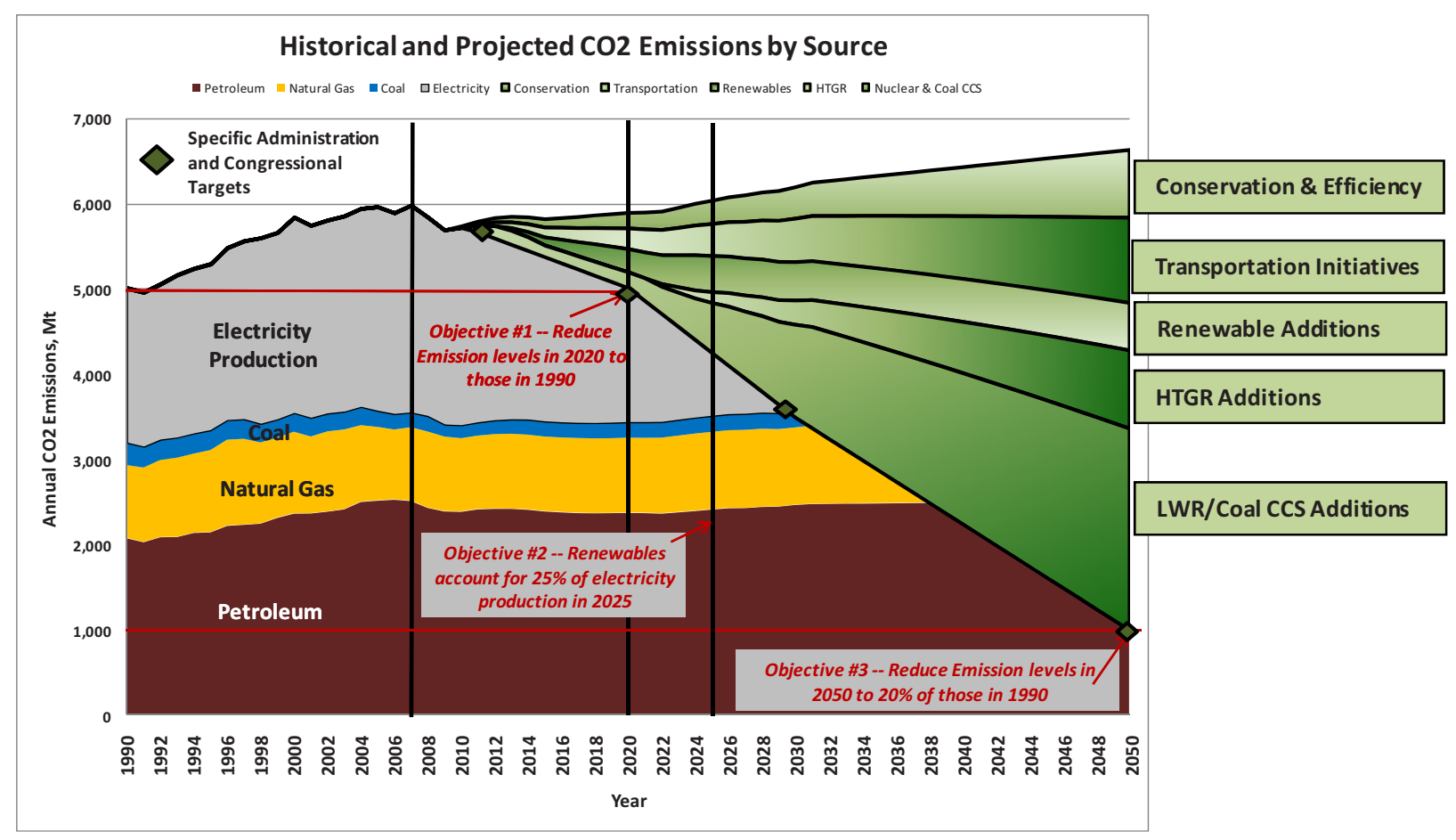

Figure 13. Results of technology based strategy application.

The initiatives of the five prong approach include:

- Conservation \& Efficiency_-Taking advantage of improving efficiency in energy production, consumption and conservation to reduce consumption at a rate of $\sim 0.25 \%$ per annum (consistent with Environmental Protection Agency estimates but higher than projected by Energy Information Administration with no emissions reduction program)

- Transportation Initiatives - Supporting more use of lower emitting transportation fuels in FLEX and hybrid vehicles, (e.g., replacing corn ethanol with cellulosic ethanol and/or other bio-fuels to improve environmental impact and reduce the impact on the food chain), use of bio-diesel in place of conventional diesel, improving vehicle mileage standards, (e.g., implementing proposed NHTSA CAFÉ standards), improving vehicle tailpipe emissions, (e.g., implementing the proposed EPA standards) and deploying hybrid and electric vehicles in place of conventional vehicles

- Renewable Additions-Increasing the use of renewables for electricity production in place of coal plants, (e.g., hydro-electric, wind, solar, biomass); fulfilling the emerging energy policy objectives of having renewables account for $25 \%$ of electricity production by 2025 and maintaining this level of production through 2050.

- HTGR Additions-Applying nuclear energy, in the form of HTGR design to replace the burning of fossil fuels in commercial and industrial applications and to provide a GHG emission free source of energy for production of synthetic fuels and chemical feedstock from coal and biomass

- LWR \& CCS Additions - Increasing the use of nuclear power and, if technically viable, coal and gasfired plants with carbon capture and sequestration (CCS), as replacements for conventional coal fired and natural gas plants for the production of electricity.

This Technology Based Strategy would result in a complete transformation that meets the criteria for correcting the vulnerabilities of the energy infrastructure in the United States: 
- It will result in meeting the full objective of lowering GHG emissions on a permanent and selfsustaining basis using indigenous rather than offshore resources.

- It will result in more secure and more predictable costs of energy, (e.g., result in significant reductions, if not complete elimination, of the need to import crude oil or natural gas).

- It will promote more effective use of our indigenous sources of energy, (e.g., use of natural gas as feedstock for petrochemical processing instead of burning it, clean application of coal, our most abundant energy source). 


\section{INFRASTRUCTURE REQUIREMENTS TO SUPPORT HTGR TECHNOLOGY DEPLOYMENT}

To identify the infrastructure requirements to support HTGR Technology Deployment, the NGNP Project awarded subcontracts to both Westinghouse and AREVA to assess the current infrastructure capability to identify development needs and recommend additional improvements required to support deployment of the NGNP, which could also apply to the deployment of follow-on HTGRs. In general, the infrastructure readiness assessment will examine the current state and plans to address the various infrastructure elements necessary to support deployment of NGNP, focusing on industrial capabilities, as opposed to laboratory infrastructure, related to equipment, fabrication, construction and start of operations for an NGNP, with an understanding that the same infrastructure could be brought to bear on follow-on HTGR deployment.

This work is being performed in two phases:

An initial assessment will include a summary of the capacities, capabilities, and readiness levels. This would entail a preliminary survey of appropriate infrastructure services. A detailed assessment will involve validating the assumptions and results made in the initial assessment. This validation will include documentation of infrastructure expansion planning or other applicable bases.

Specific topics to be addressed in the infrastructure assessment include:

A. Ability of suppliers to provide equipment and materials of construction and/or fabricate NGNP components. This includes metallic, graphite, and ceramic materials of construction. Potential suppliers will also be identified in the final deliverable.

B. Ability of suppliers to perform in accordance with an NQA-1 quality program. For graphite, coke source-based, and other non-metallic components, the subject of reproducibility shall also be addressed.

C. Transportation capability for moving the equipment and materials in their appropriate shapes and sizes to meet the needs of the necessary components.

D. Readiness level of skilled labor forces needed to accomplish the various phases of manufacturing/fabrication, construction, transportation, and start-up.

E. Availability of construction capabilities and techniques necessary to build an NGNP.

Special attention will be given to the current state, plans to change the current state in response to market drivers or anticipated needs, anticipated future states and their dates of readiness, and additional changes beyond current planning needed to address NGNP deployment (which could also apply to follow-on HTGR deployment).

To date, Westinghouse and AREVA have completed the initial assessment effort. Their Initial NGNP Infrastructure Readiness Assessment Reports are currently being reviewed by the NGNP Project. At the conclusion of this review, the NGNP Project will prepare a summary report of the Initial NGNP Infrastructure Readiness Reports by September 30, 2010. The detailed assessment is scheduled to be completed in December 2010. 


\section{A COMPARISON OF THE DOE AND NGNP INDUSTRY ALLIANCE PROJECT IMPLEMENTATION STRATEGIES}

In the April 2010 DOE Report to Congress on the status of the NGNP Project a cost estimate, cost share provisions and milestone schedule were presented for completing the NGNP Project. On November 30, 2009 the NGNP Industry Alliance Limited ${ }^{\text {d }}$, submitted a proposed Project Implementation Strategy to DOE Secretary Chu that also included cost estimates, cost share provisions and a milestone schedule for completing the NGNP Project. The Alliance Strategy was emphasized in a subsequent letter to Secretary Chu in June 2010. Although the DOE and Alliance submittals have the objective of initiating operation of a FOAK reactor module(s) by 2021 as required by the EPAct there are significant differences in the detailed strategies proposed to get to that point.

The major differences between the DOE strategy for project completion and that of the NGNP Industry Alliance are four fold:

- Decision making framework, including the authority for making the decisions:

- The DOE strategy includes a recommendation to the Secretary whether to proceed. This recommendation will be partially informed by a review of the Nuclear Energy Advisory Council (NEAC). If the NGNP Project is to proceed, the DOE will initiate a competitive process to initiate Phase 2 of the Project in June 2011 with a decision to down-select one high temperature gascooled reactor (HTGR) design in Sept 2011.

- The Alliance proposes to jointly develop with the DOE the functional \& performance requirements for the HTGR plants based on end user needs and to continue with the several stages of design development and licensing as jointly decided by DOE and the Alliance for two reactor concepts - one based on a pebble bed reactor concept and one on the prismatic block reactor concept. Decisions on which design work to complete and which Combined License Applications (COLAs) will be prepared for the FOAK plant(s) would be determined by Owners of the plants in mid-2011 and decisions to construct by the future Owners and End Users in mid2017

- Schedule to proceed:

- The DOE expects a cooperative agreement with a supplier in 2011 with COLA preparation September 2011 to September 2013. It is noted that the current DOE planning for design development does not support this schedule.

- The Alliance proposes establishing the public-private partnership in the $4^{\text {th }}$ Quarter of 2010 , initiating full design activities and continuing licensing activities in parallel with forming the partnership, preparing Early Site Permit (ESP) applications starting in October 2010 and preparing COLAs for two sites starting mid-2011 to 2014.

- Scope of project:

- DOE expects to down-select to one design in September 2011

- The Alliance carries two designs through preparation of COLAs in mid-2014 with the Owners deciding whether to construct one or two plants in early 2017.

- Cost share model:

- DOE cost share is 50/50 overall each year for all scope except applied research and development

d The NGNP Industry Alliance Limited, is an industry consortium formed with the assistance of the Idaho National Laboratory as directed by EPAct 2005 and the Battelle Energy Alliance contract with DOE. The Alliance members include energy end-users representing the petrochemical and petroleum industries, a nuclear owner/operator, nuclear system suppliers, a nuclear fuel and equipment vendor, and an architect-engineer/constructor. 
- Alliance proposed cost share is 50/50 cumulative overall costs with the government share primarily through preliminary design and during the licensing stages. The private sector would fund all construction and operating costs. A more detailed comparison of cost sharing is presented in Section 3.

Table 1. Proposed public and private sector cost shares.

\begin{tabular}{|c|c|c|c|c|c|}
\hline \multicolumn{4}{|c|}{ One First-of-a-Kind Reactor Module } & \multirow{2}{*}{\multicolumn{2}{|c|}{$\begin{array}{c}\text { Two First-of-a-Kind Reactor Modules } \\
\text { NGNP Industry Alliance PIS }\end{array}$}} \\
\hline \multicolumn{2}{|c|}{ DOE Report to Congress } & \multicolumn{2}{|c|}{ NGNP Industry Alliance PIS } & & \\
\hline Gov't Share, \$M & $\begin{array}{l}\text { Private Sector } \\
\text { Share }\end{array}$ & Gov't Share & $\begin{array}{c}\text { Private Sector } \\
\text { Share }\end{array}$ & Gov't Share & $\begin{array}{l}\text { Private Sector } \\
\text { Share }\end{array}$ \\
\hline$\$ 2,192 \mathrm{M}$ & $\$ 1,757 \mathrm{M}$ & $\$ 1,633 \mathrm{M}$ & $\$ 2,645 \mathrm{M}$ & $\$ 1,732 \mathrm{M}$ & $\$ 4,950 \mathrm{M}$ \\
\hline
\end{tabular}

These summary differences are not a comprehensive description of the results of a detailed gap analysis, but rather are those differences that warrant discussion in meetings between DOE executives and the private sector represented by the Alliance. In practical fact, the full range and content of the differences will not be understood until such time as detailed discussions are engaged between the DOE and the private sector Alliance to develop a mutually agreed-to project execution plan. 